\title{
Branqueamento de corais nos recifes da Bahia e sua relação com eventos de anomalias térmicas nas águas superficiais do oceano
}

\author{
Zelinda Margarida Andrade Nery Leão ${ }^{1,2}$, Ruy Kenji Papa de Kikuchi ${ }^{1}$ \& \\ Marília de Dirceu Machado de Oliveira ${ }^{1}$ \\ ${ }^{1}$ Curso de Pós-Graduação em Geologia - CPGG, Universidade Federal da Bahia - UFBA, \\ Rua Barão de Jeremoabo, s/n, Ondina, CEP 40170-115, Salvador, BA, Brasil \\ ${ }^{2}$ Autor para correspondência: Zelinda Leão,e-mail: zelinda@ufba.br
}

LEÃO, Z.M.A.N., KIKUCHI, R.K.P. \& OLIVEIRA, M.D.M. 2008. Coral bleaching in Bahia reefs and its relation with sea surface temperature anomalies. Biota Neotrop. 8(3): http://www.biotaneotropica.org.br/ v8n3/en/abstract?article+bn00808032008.

\begin{abstract}
Since 1993 several coral bleaching events were registered in Bahia. There were no mass coral death associated to these events and the affected corals fully recovered after the impact. The first occurrence was registered during the southern hemisphere summer of 1993/1994, in Abrolhos, when 50 to $90 \%$ of the coral colonies were bleached. In the North Coast of Bahia, during the summer of 1997/1998, a sea surface temperature (SST) anomaly of $1{ }^{\circ} \mathrm{C}$ matched with SST registered in the field $\left(29\right.$ to $\left.30.5^{\circ} \mathrm{C}\right)$. As a result, up to $60 \%$ corals bleached. From 1998 to 2005 anomalies of $0.25^{\circ} \mathrm{C}$, for two weeks, caused bleaching in more than $10 \%$ corals from the coastal reefs, which are located adjacent or less than $5 \mathrm{~km}$ from the coastline. However in the Abrolhos region, where reefs are located more than $10 \mathrm{~km}$ from the continent, only SST anomalies higher than $0.50{ }^{\circ} \mathrm{C}$, persisting for more than two weeks, caused bleaching up to $10 \%$ of the investigated corals. Mussismilia hispida, Siderastrea spp., Montastraea cavernosa, Agaricia agaricites and Porites astreoides were the coral species most severely impacted by bleaching, and they are also the most common species in the coastal reefs. All species presented different levels of bleaching, 'light' or 'heavy'. In Bahia, there is a strong linkage between coral bleaching and periods of elevated sea surface temperature, and the most affected corals were the ones from the coastal reefs. These coastal reefs are exposed to the impacts from processes occurring in the continent, suggesting that corals exposed to high levels of nutrient and sediment loads, and large SST fluctuations, may be more resistant to the post bleaching effects, such as infectious diseases and mass mortality.
\end{abstract}

Keywords: temperature anomaly, coral reef, Abrolhos, Todos os Santos Bay, coral bleaching.

LEÃO, Z.M.A.N., KIKUCHI, R.K.P. \& OLIVEIRA, M.D.M. 2008. Branqueamento de corais nos recifes da Bahia e sua relação com eventos de anomalias térmicas nas águas superficiais do oceano. Biota Neotrop. 8(3): http://www.biotaneotropica.org.br/v8n3/pt/abstract?article+bn00808032008.

Resumo: A partir de 1993 foram registrados vários eventos de branqueamento de coral na Bahia, com recuperação total dos corais afetados. O primeiro registro ocorreu em Abrolhos no verão de 1993/1994, quando o percentual de colônias branqueadas variou entre 50 e 90\%. No verão de 1997/1998, ocorreu no Litoral Norte da Bahia uma anomalia térmica de $1{ }^{\circ} \mathrm{C}$, com temperaturas medidas no campo de 29 a $30,5^{\circ} \mathrm{C}$, o que causou branqueamento em $60 \%$ dos corais. De 1998 a 2005, foi observado que nos recifes costeiros, localizados muito próximos $(<5 \mathrm{~km})$ ou adjacentes à costa, a permanência de anomalias térmicas de $0,25^{\circ} \mathrm{C}$ por mais de duas semanas causou branqueamento em mais de $10 \%$ dos corais. Porém para os recifes de Abrolhos, localizados a mais de $10 \mathrm{~km}$ da costa, apenas anomalias acima de $0,50{ }^{\circ} \mathrm{C}$ com duração de mais de duas semanas causaram branqueamento em mais de $10 \%$ dos corais. Mussismilia hispida, Siderastrea spp., Montastraea cavernosa, Agaricia agaricites e Porites astreoides foram as espécies de coral mais afetadas pelo branqueamento e são as espécies mais frequientes nos recifes costeiros. Todas as espécies apresentaram graus diferentes de branqueamento, "fraco" ou "forte". Nos recifes da Bahia há uma forte relação entre o branqueamento de corais e os eventos de anomalias da temperatura da superfície do mar (TSM), e os recifes mais afetados pelo branqueamento foram os recifes costeiros. Estes recifes localizados muito próximos da costa estão mais expostos aos efeitos dos impactos provenientes de processos que ocorrem na região costeira, sugerindo que, muito provavelmente, os corais mais expostos a níveis elevados de nutriente e sedimento, e variações sazonais mais altas da TSM, podem já estarem mais resistentes aos efeitos pós branqueamento como, por exemplo, doenças infecciosas e mortalidade em massa.

Palavras-chave: anomalias térmicas, recife de coral, Abrolhos, Baía de Todos os Santos, branqueamento. 


\section{Introdução}

Os recifes de corais constituem o mais diverso, mais complexo e mais produtivo dos ecossistemas marinhos costeiros (Connell 1978). Eles fornecem alimento e são a principal fonte de recursos econômicos para centenas de milhares de pessoas que vivem nas regiões tropicais do nosso planeta (Moberg \& Folke 1999). Estimativas da área global de recifes de coral, em mais de 100 países, registram um total de $0,5 \%$ da superfície do fundo oceânico, o que equivale a um máximo de $1.500 .000 \mathrm{~km}^{2}$ (Copper 1994). Deste total, calcula-se que cerca ou até mais de $30 \%$ dos recifes já estejam severamente danificados e que dentro de trinta a quarenta anos aproximadamente $60 \%$ das áreas recifais do mundo estarão totalmente degradadas, particularmente em consequiência da ação sinérgica da depredação dos recursos naturais devido à ação do homem, sobretudo da sobre-pesca e da poluição marinha, e das mudanças climáticas globais (Wilkinson 2002, Gardner et al. 2003, Knowlton \& Jackson 2008). Recifes prístinos não devem mais existir, ou são muito raros nos oceanos atuais (Jackson et al. 2001, Pandolfi et al. 2003).

Os ecossistemas recifais são extremamente sensíveis a variações da temperatura das águas oceânicas (Glynn 1993). Um aumento relativamente pequeno da temperatura das águas superficiais pode provocar a ocorrência do branqueamento, que é um processo relacionado à perda, pelos corais, das algas fotossintetizantes - as zooxantelas, que estão presentes no tecido dos corais e que participam de uma cooperação vital que beneficia ambos os organismos, e/ou a perda dos pigmentos por estas algas zooxantelas (Szmant \& Gassman 1990, Fautin \& Buddemeier 2004). As zooxantelas, além de darem a cor ao coral, produzem componentes orgânicos que lhes servem de alimento e, em contrapartida, o coral provê abrigo para as algas e lhes fornece elementos químicos necessários à sua sobrevivência (Muscatine 1990, Muller-Parker \& D'Elia 1997, Stanley Jr. 2006). Distúrbios ambientais podem interromper esta delicada simbiose, causando dissociação entre as algas e os corais (Kühlmann 1988, Birkeland 1997). Neste caso o coral perde a sua cor, exibindo o esqueleto calcário branco, o que originou o nome branqueamento. A incidência e a severidade do fenômeno de branqueamento dos corais podem provocar mudanças substanciais na estrutura das comunidades do ecossistema recifal, tanto no que diz respeito à sua biodiversidade, reprodução, diminuição do crescimento linear e redução da taxa de calcificação do esqueleto dos corais e, conseqüentemente, da manutenção e do desenvolvimento da estrutura recifal (Goreau \& MacFarlane 1990, Glynn 1993, Fitt et al. 1993, Brown 1997, Wilkinson et al. 1999, Michalek-Wagner \& Willis 2001).

Em várias partes do globo, como também no Brasil, o fenômeno de branqueamento de corais parece coincidir com o aquecimento dos oceanos durante a ocorrência de eventos El-Niño, evidenciando que variações da temperatura das águas superficiais do mar afetam os ecossistemas tropicais, particularmente os recifes de coral (Glynn 1990, Brown \& Ogden 1993, Migotto 1997, Castro \& Pires 1999, Walther et al. 2002, Kikuchi et al. 2003, Leão et al. 2003, Oliveira et al. 2004).

As referências publicadas sobre o branqueamento de coral no Brasil, anteriores aos eventos estudados durante a realização deste trabalho, dizem respeito a: i) um evento que ocorreu na costa do Estado de São Paulo no verão de 1993/1994 (Migotto 1997), o qual foi relacionado a um aumento anormal da temperatura das águas oceânicas; ii) outro evento no Litoral Norte do estado da Bahia, no verão de 1997/1998 (Dutra 2000, Dutra et al. 2000), coincidente com anomalias térmicas ocorridas neste período, iii) duas ocorrências em Abrolhos, no sul da Bahia, no verão de 1993/1994 (Castro \& Pires 1999) e no verão de $1997 / 1998$, que também estão relacionadas com aumento da temperatura das águas oceânicas (Leão et al. 2003,
Oliveira et al. 2004), e iv) dois registros na costa nordeste do Brasil; o primeiro no ano de 1996 quando Costa et al. (2001), Costa \& Amaral (2002), Costa et al. (2004) analisando o branqueamento dos corais relacionado com alterações na densidade populacional dos seus simbiontes observaram que durante os meses em que a temperatura da água alcançou valores entre 29 e $30{ }^{\circ} \mathrm{C}$, as colônias dos corais branquearam, retornando à sua coloração normal nos meses com temperaturas mais amenas (entre 26 e $28{ }^{\circ} \mathrm{C}$ ). $\mathrm{O}$ segundo registro na costa nordeste do Brasil é para o ano de 2003, quando Ferreira e Maida (2006) relatam a ocorrência de branqueamento em cerca de 3\% das colônias dos corais investigados no Atol das Rocas, em 1,5\% nos corais das ilhas de Fernando de Noronha, e percentuais de colônias branqueadas variando entre 2 e $12 \%$ nos recifes da costa do estado de Pernambuco.

No evento de São Paulo as espécies de coral mais afetadas foram Mussismilia hispida Verrill 1868 e Madracis decactis Lymann 1859 (Migotto 1997). No Litoral Norte da Bahia, três espécies de corais, Agaricia agaricites Linne 1758, Mussismilia hispida e Siderastrea spp., as quais apresentaram a maior abundância relativa, tiveram de 20 a $80 \%$ de suas colônias afetadas (Dutra et al. 2000). Em Abrolhos, a ocorrência de branqueamento que ocorreu durante uma anomalia de temperatura no verão de 1993/1994, percentagens de 51 a $88 \%$ das colônias do gênero Mussismilia foram afetadas (Castro \& Pires 1999), e durante o fenômeno relacionado com o forte evento El-Niño que se iniciou no final de 1997 no oceano Pacífico e causou, também, um aumento da temperatura das águas na costa do Brasil, cerca de nove espécies de corais apresentaram suas colônias parcial ou totalmente branqueadas com percentuais variando entre 10 e $90 \%$, entre as quais A. agaricites, $M$. hispida e Porites astreoides Lamark 1859 foram as espécies de corais que apresentaram níveis mais elevados de branqueamento (Leão et al. 2003). Para a costa nordeste do Brasil, Costa et al. $(2001,2004)$ citam eventos de branqueamento na espécie Siderastrea stellata Verrill 1868.

O objetivo deste trabalho é descrever as ocorrências de branqueamento dos corais em várias áreas recifais ao longo da costa leste do Brasil (Estado da Bahia), observadas durante o período do final do verão e início do outono, isto é, entre os meses de fevereiro e abril dos anos de 1998 a 2005, relacionando-as com possíveis eventos de aquecimento das águas superficiais do oceano. Estão descritas, também, as espécies de coral e de milepora que foram afetadas durante os episódios de branqueamento. O banco de dados utilizado para o trabalho inclui cerca de 10.500 colônias de corais avaliadas em 27 recifes durante 112 inspeções de campo.

\section{Material e Métodos}

\section{Locais de estudo}

Os recifes de coral investigados durante este trabalho estão localizados em seis regiões ao longo da costa do Estado da Bahia: Litoral Norte $\left(12^{\circ} 22,50^{\prime} \mathrm{S}\right.$ e $\left.38^{\circ} 01,11^{\prime} \mathrm{W}\right)$, Baía de Todos os Santos $\left(12^{\circ} 28,12^{\prime}-13^{\circ} 00,00^{\prime} \mathrm{S}\right.$ e $\left.38^{\circ} 18,00^{\prime}-38^{\circ} 27,01^{\prime} \mathrm{W}\right)$, Ilhas de Tinharé e Boipeba e Baía de Camamu (13 $12,04^{\prime}-14^{\circ} 00,00^{\prime} \mathrm{S}$ e $\left.38^{\circ} 54,09^{\prime} \mathrm{W}\right)$, Cabrália $\left(16^{\circ} 14,23^{\prime} \mathrm{S}\right.$ e $\left.38^{\circ} 57,09^{\prime} \mathrm{W}\right)$, Recifes dos Itacolomis ( $16^{\circ} 53,51^{\prime} \mathrm{S}$ e $\left.39^{\circ} 05,27^{\prime} \mathrm{W}\right)$ e Abrolhos $\left(17^{\circ} 27,58^{\prime}-18^{\circ} 01,13^{\prime}\right.$ 'S e $38^{\circ} 40,16^{\prime}-39^{\circ} 00,34^{\prime}$ W) (Figura 1).

No Litoral Norte da Bahia (LN) foram levantados dados durante o ano de 1998, tendo sido observado branqueamento em abril, nos recifes isolados localizados nas proximidades das praias de Guarajuba e de Itacimirim (Dutra 2000, Dutra et al. 2000).

Na Baía de Todos os Santos (BTS) foram coletados dados de branqueamento em um recife (Caramuanas) localizado em frente à ilha de Itaparica, na entrada da baía, no mês de outubro de 1998 


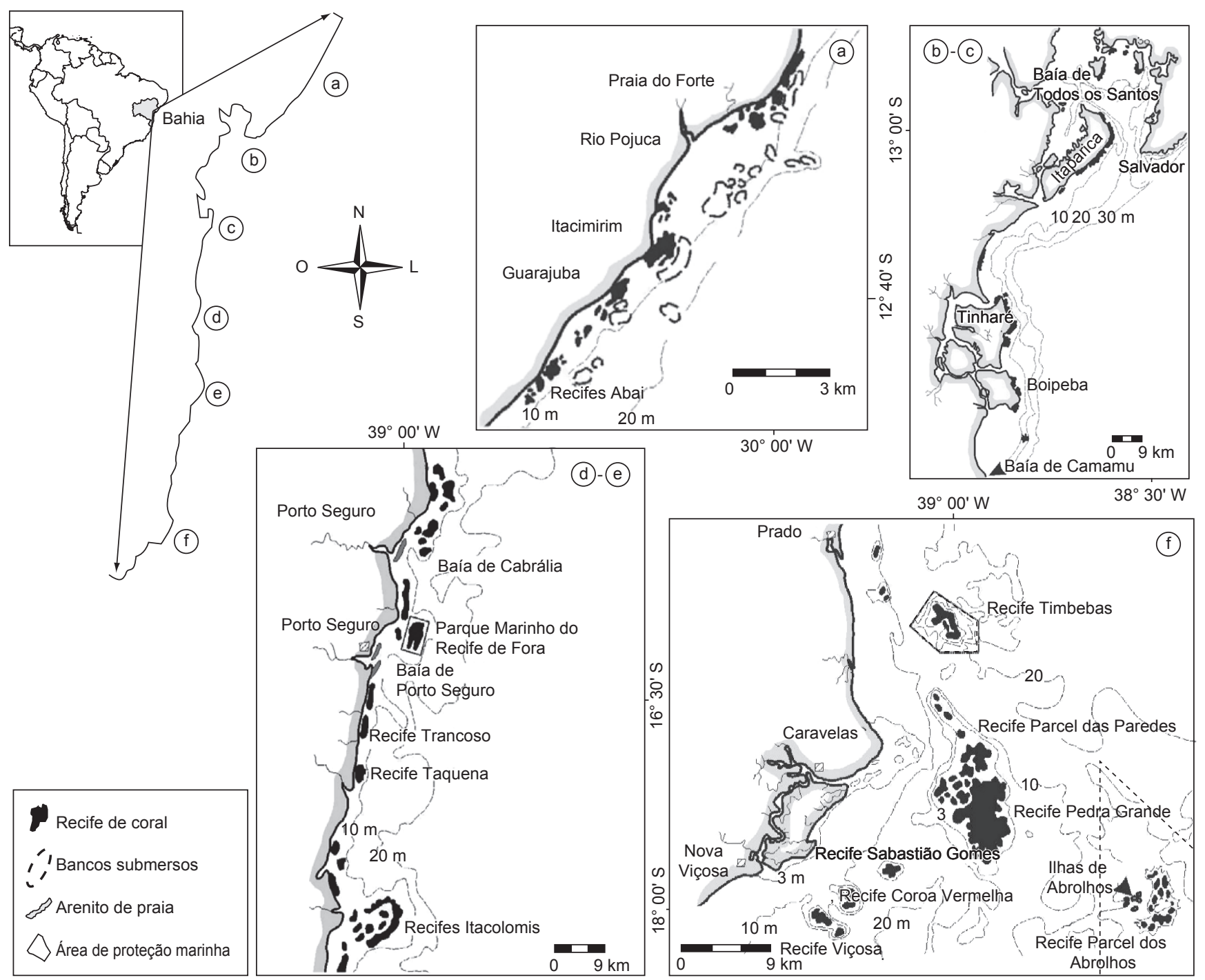

Figura 1. Localização dos recifes estudados; a) Litoral Norte; b-c) Baía de Todos os Santos e ilhas de Tinharé e Boipeba; d-e) Cabrália e Itacolomis; e f) Abrolhos.

Figure 1. Location of studied reefs; a) North Coast; b-c) Todos os Santos Bay and Tinharé and Boipeba Islands; d-e) Cabrália and Itacolomis; and f) Abrolhos.

(Leão et al. 1999), e em quatro estações localizadas na região centroleste da baía, nos meses de abril e maio de 2003 (Dutra et al. 2006). Nestes recifes não foi avaliado o percentual de branqueamento por espécie de coral, e por esta razão eles não estão citados nas Tabelas 2 e 3 .

As ilhas de Tinharé e de Boipeba (T/B) estão localizadas entre as baías de Todos os Santos e de Camamu. Nos recifes em franja que bordejam estas ilhas foram avaliadas quatro estações no mês de março de 2002, três no mês de abril de 2003 e três no mês de fevereiro de 2004. Nas proximidades da Baía de Camamu foi avaliado um recife também no mês de fevereiro de 2004.

Na região de Cabrália foram avaliados seis recifes no mês de setembro de 2004.

Os recifes dos Itacolomis (ITA) estão localizados em frente à Ponta de Corumbau, entre as regiões de Porto-Seguro e Abrolhos (Figura 1). Eles fazem parte da Reserva Extrativista de Corumbau, a qual abrange áreas dentro dos municípios de Prado e Porto-Seguro, estendendo-se das praias em direção costa - afora. No mês de abril de 2005 foram avaliados três recifes.
Na região de Abrolhos, no mês de março dos anos de 2000 a 2004 e no final do mês de abril de 2005, foram coletados dados de branqueamento em três áreas distintas de recifes: nos recifes que compõem o Arco Costeiro (ABC), os recifes em franja que bordejam as cinco ilhas do Arquipélago dos Abrolhos (ABA) e nos chapeirões gigantes que compõem o Arco Externo de recifes - o Parcel dos Abrolhos (PAB).

\section{Técnicas de avaliação}

\subsection{Levantamento dos dados climáticos (ocorrência de hot spots) na internet}

O acompanhamento das variações da temperatura da água, na costa do estado da Bahia, foi feito utilizando-se as cartas de anomalias térmicas da superfície do mar e as indicações dos "hot spots" para branqueamento de corais, produzidas pela equipe ORA/OSDPD/ NOAA, e disponíveis na rede mundial INTERNET, no seguinte portal: http://www.osdpd.noaa.gov/PSB/EPS/SST/climohot.html. 
Os dados de anomalias térmicas (hot spots) foram obtidos para os anos de 1998 a 2005, no período entre os meses de fevereiro e maio, os quais correspondem ao final do verão e início do outono, no hemisfério sul, quando houve ocorrência das temperaturas mais elevadas das águas superficiais dos oceanos na costa do Brasil. Segundo Goreau \& Hayes (1994) um hot spot ocorre quando, em uma determinada área, a temperatura das águas superficiais excede o máximo anual alcançado num período de 10 anos. Se a anomalia de $1{ }^{\circ} \mathrm{C}$ persistir por um mínimo de quatro semanas, prevê-se o branqueamento em massa de coral (Wilkinson et al. 1999, Wilkinson \& Souter 2008). Este valor foi atingido, no verão de 1998 no Litoral Norte, no verão 2002/2003 em Abrolhos, na área das ilhas de Tinharé e Boipeba e no Litoral Norte do estado. Valores iguais a $0,75^{\circ} \mathrm{C}$ ocorreram no ano de 2003, na Baía de Todos os Santos (BTS), e nos anos de 2001, 2002 e 2005, na região de Abrolhos. No ano de 2005, anomalias com valor de $0,50{ }^{\circ} \mathrm{C}$ ocorreram nas regiões de Tinharé e Boipeba, Porto-Seguro e Baía de Todos os Santos. Nos anos de 2000 e 2004, as anomalias da temperatura da água tiveram valores máximos de apenas $0,25^{\circ} \mathrm{C}$ nas regiões de Tinharé e Boipeba e de Abrolhos.

\subsection{Aquisição dos dados de campo}

Os trabalhos de campo foram desenvolvidos de acordo com a técnica proposta no Protocolo AGRRA (Atlantic and Gulf Rapid Reef Assessment, Ginsburg et al. 1998) e a técnica do vídeo transécto (Aronson et al. 1997, Carleton \& Done 1995, Page et al. 2001).

A técnica utilizada para a coleta dos dados descrita no protocolo AGRRA tem como princípio a utilização de senso visual ao longo de transéctos e em quadrados. Para avaliar as condições dos corais ao longo de transéctos estende-se, aleatoriamente, a trena graduada, de $10 \mathrm{~m}$ de comprimento, paralelamente ao eixo maior dos recifes e estima-se o percentual de cobertura de coral vivo, medindo-se a extensão da superfície viva de cada colônia de coral presente sob a linha do transécto. Em seguida avalia-se cada colônia de coral maior que $20 \mathrm{~cm}$ que ocorre até $50 \mathrm{~cm}$ de cada lado da linha do transécto (uma banda de $1 \mathrm{~m}$ de largura), registrando-se: nome (gênero e espécie), diâmetro máximo; porcentagem (\%) morta da superfície da colônia (morte recente e morte antiga) vista em planta, e a presença de doenças e/ou branqueamento. Dentro dos quadrados $(25 \times 25 \mathrm{~cm})$, os quais são colocados nas posições de 1, 3, 5, 7 e 9 m ao longo do transécto, estima-se o percentual de cada tipo de alga: filamentosa (turf), foliácea (macro) e coralinácea crustosa, e conta-se o número de recrutas de coral (colônias $<2 \mathrm{~cm}$ de diâmetro).

Esta técnica foi aplicada na investigação dos recifes das Caramuanas na entrada da Baía de Todos os Santos, nos recifes das ilhas de Tinharé e Boipeba, na região de Cabrália, nos recifes dos Itacolomis e na região de Abrolhos. Nos recifes das Caramuanas foi investigado apenas um recife em 1998, usando-se o censo visual ao longo de transéctos como proposto no protocolo AGRRA. Em Tinharé e Boipeba, no ano de 2003, foram investigados quatro recifes usando-se seis transéctos de $10 \mathrm{~m}$ e 30 quadrados $(25 \times 25 \mathrm{~cm})$ em cada recife. Na região de Cabrália, em 2004, foram investigados seis recifes aplicando-se o mesmo número de transéctos e quadrados que nos recifes de Tinharé e Boipeba. E este mesmo padrão foi usado para investigar três recifes dos Itacolomis, em 2005. Na região de Abrolhos, durante os anos de 2000 a 2005, foram investigados cinco recifes do arco costeiro, os recifes em franja das cinco ilhas que compõem o Arquipélago dos Abrolhos e os chapeirões do Parcel dos Abrolhos, num total de quarenta levantamentos. À semelhança dos recifes descritos anteriormente, foram aplicados seis transéctos e 30 quadrados em cada levantamento em cada recife.

A técnica do vídeo transécto é relativamente recente no Brasil (Dutra et al. 2006), tendo sido uma iniciativa pioneira para o diagnóstico dos recifes de coral da Baía de Todos os Santos (BTS).
Para a filmagem submarina foi usada uma câmera de vídeo digital de alta resolução, Sony ${ }^{\circledR}$ MINI DV, modelo DCR-PC115, dentro de uma caixa estanque CHROMA $^{\circledR}$. Uma régua de alumínio foi acoplada à caixa estanque, definindo o comprimento da haste de $40 \mathrm{~cm}$ o que permitiu que a câmera permanecesse a uma distância constante do substrato, definindo uma área do quadro de filmagem de $0,04 \mathrm{~m}^{2}$. Definiu-se o comprimento de um transécto de $20 \mathrm{~m}$ e dessa forma, a área total investigada de cada recife foi de seis transéctos $\times 20 \mathrm{~m} \times 0,04 \mathrm{~m}^{2}$, ou seja, $4,8 \mathrm{~m}^{2}$. Os transéctos foram aleatoriamente localizados dentro do habitat de interesse onde um mergulhador, operando a câmera, nadou a uma velocidade constante de $3 \mathrm{~m} / \mathrm{min}$ (que se mostrou a melhor velocidade para reproduzir uma imagem de boa qualidade), com a câmera posicionada perpendicularmente ao substrato. Desta forma foi possível produzir imagens que ao serem congeladas ofereceram uma ótima resolução. No laboratório foi obtida uma seqüência completa de quadros que documentaram toda a extensão do transécto. Sobre cada quadro aberto em tela cheia, foi colocada, sobre o monitor, uma transparência onde se diagramou uma malha de 100 pontos eqüidistantes. Foram sorteados 10 pontos em cada quadro e identificados os organismos que se encontravam abaixo deles. Em cada transécto foram adquiridos cerca de 100 quadros, com identificação de organismos em aproximadamente 1.000 pontos em cada transécto de $20 \mathrm{~m}$.

No Litoral Norte os levantamentos foram realizados aplicando-se a técnica do transécto em banda ( $1 \mathrm{~m}$ de largura $\times 10$ m comprimento). Para acompanhar a recuperação dos corais branqueados a cada mês, durante um ano, os corais foram avaliados ao longo de quatro transéctos paralelos ao eixo maior do recife.

\section{Resultados}

\section{Acompanhamento da ocorrência de branqueamento dos corais}

De 1998 a 2005, com exceção da região de Cabrália, em todas as áreas de recifes de corais avaliadas ao longo da costa do Estado da Bahia, foi verificada a presença de coral com algum grau de branqueamento, seja ele fraco ou colônias fortemente branqueadas. A categoria de branqueamento "Fraco" é atribuída à área das colônias dos corais que se apresenta ligeiramente pálida e a "Forte", àquela em que a superfície da colônia está parcial ou totalmente branca. Nas Figuras 2 a 5 estão ilustradas as ocorrências de hot spots na costa da Bahia e os percentuais de colônias branqueadas correspondentes a cada evento de anomalia térmica. A Figura 6 ilustra os tipos de branqueamento registrados.

1998 - A temperatura das águas ao norte da cidade de Salvador, apresentou sinais de anomalia térmica a partir de meados do mês de janeiro de 1998 , atingindo máximas de $1{ }^{\circ} \mathrm{C}$ entre os dias 21 de março e 4 de abril, retornando ao normal a partir do dia 19 de maio (Figura 2a). Duas áreas de recifes de coral foram avaliadas, uma no Litoral Norte do estado, onde a média do percentual de colônias com algum grau de branqueamento atingiu um valor acima de $50 \%$, e outra no recife das Caramuanas, onde foi observado um total de $18 \%$ de colônias com sinal de branqueamento (Figura 3a). A primeira avaliação realizada no Litoral Norte ocorreu no dia 14 de abril, quando a temperatura medida na superfície do mar atingiu $30,5^{\circ} \mathrm{C}$, e cerca de $40 \%$ das colônias dos corais apresentavam algum grau de branqueamento. No dia 17 de abril este percentual ultrapassou de $80 \%$. Este evento de branqueamento foi acompanhado durante um ano e em dezembro de 1998, todas as colônias afetadas já haviam recuperado sua coloração normal (Dutra et al. 2000). O levantamento nos recifes das Caramuanas foi realizado seis meses após a ocorrência do hot spot no norte da Bahia, quando foi observado que cerca de 

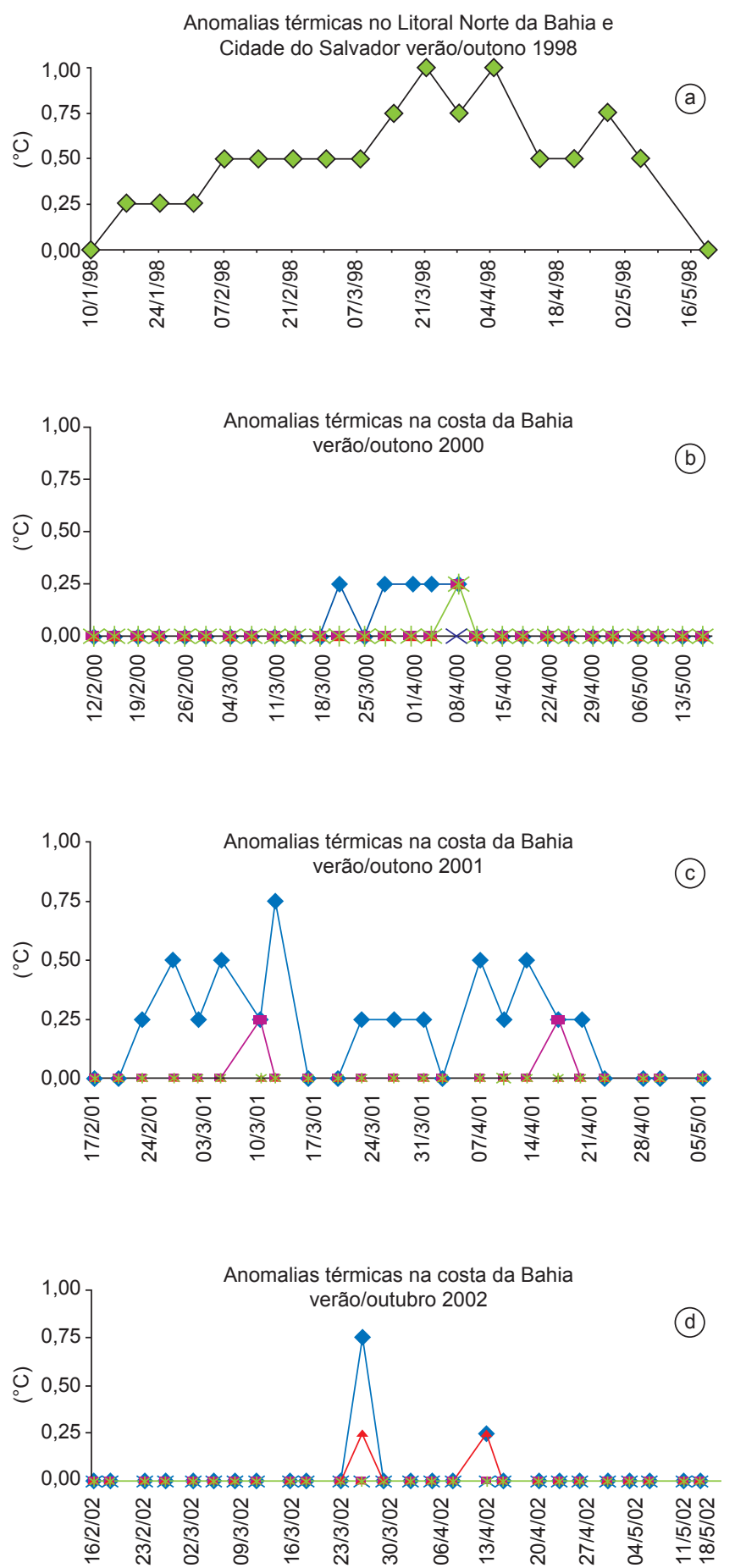

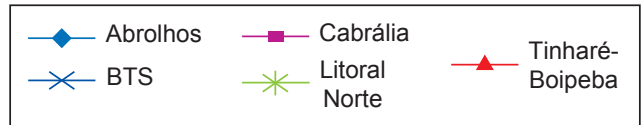

Figura 2. a) Anomalias da temperatura das águas superficiais oceânicas para a costa do Estado da Bahia, obtidas de imagens orbitais. Fonte: http://www. osdpd.noaa.gov/PSB/EPS/SST/climohot.html; 1998 Litoral Norte; b) 2000; c) 2001 ; e d) 2002 .

Figure 2. a) Sea surface temperature anomalies for the coast of the state of Bahia, taken from orbital images. Source: http://www.osdpd.noaa.gov/ PSB/EPS/SST/climohot.html; 1998 - North Coast; b) 2000; c) 2001; and d) 2002 .
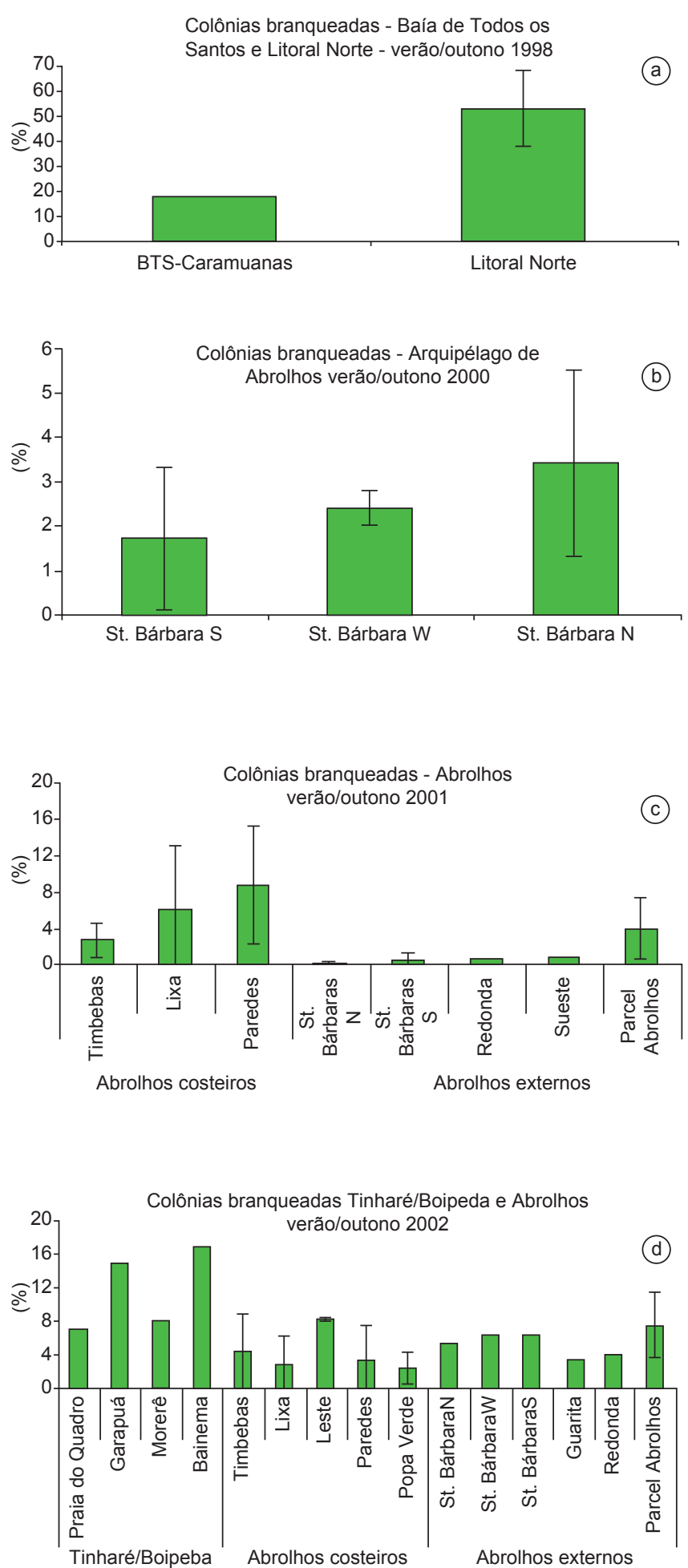

Figura 3. a) Branqueamento de corais expresso em termos de porcentagem de colônias afetadas; 1998 - recife das Caramuanas, na entrada da Baía de Todos os Santos (outubro) e no Litoral Norte (março); b) 2000 (março) recifes da ilha St. Bárbara no Arquipélago dos Abrolhos; c) 2001 (março) recifes costeiros e externos de Abrolhos; e d) 2002 (março) recifes das ilhas de Tinharé e Boipeba e recifes costeiros e externos de Abrolhos.

Figure 3. a) Coral bleaching expressed in percentage of affected colonies; 1998 - Caramuanas reef, at the entrance of Todos os Santos Bay (October) and the North Coast reefs (March); b) 2000 (March) - St. Barbara reef in the Abrolhos Archipelago; c) 2001 (March) Abrolhos coastal and offshore reefs; and d) 2002 (March) Tinharé and Boipeba Islands reefs and the Abrolhos coastal and offshore reefs. 
$20 \%$ dos corais avaliados apresentavam sinais de branqueamento (Leão et al. 1999).

2000 - O valor máximo da anomalia térmica observada foi de $0,25^{\circ} \mathrm{C}$ entre os dias 21 e 28 de março e 1 e 8 de abril, em Abrolhos, e no dia 8 de abril em Cabrália, Tinharé e Boipeba e no Litoral Norte (Figura 2b). Em março foi realizada uma inspeção nos recifes franjantes das ilhas do Arquipélago dos Abrolhos, onde o percentual de colônias com sinais de branqueamento apresentou valores inferiores a $4 \%$ (Figura 3b).

2001 - As anomalias térmicas registradas para a costa da Bahia atingiram o litoral sul do estado, particularmente a região de Abrolhos, onde o primeiro registro ocorreu no dia 23 de fevereiro com $0,25^{\circ} \mathrm{C}$, atingindo o máximo de $0,75^{\circ} \mathrm{C}$ no dia 12 de março e desaparecendo no final do mês de abril (Figura 2c). A expedição realizada durante o mês de março nessa região registrou ocorrência de corais branqueados nos recifes do arco interno, onde o percentual máximo atingido foi de $11 \%$ das colônias, nos recifes das ilhas o máximo observado foi de $1 \%$ e nos chapeirões do arco externo, o Parcel dos Abrolhos, a média de colônias com sinais de branqueamento atingiu o valor de $5 \%$ (Figura 3c).

2002 - No dia 26 de março de 2002 foi registrada a primeira anomalia térmica na costa da Bahia em Abrolhos e em Tinharé e Boipeba, atingindo 0,75 e $0,25{ }^{\circ} \mathrm{C}$, respectivamente. Uma nova ocorrência foi registrada no dia 13 de abril com máximo de $0,25^{\circ} \mathrm{C}$, nestes mesmos locais, desaparecendo a seguir (Figura 2d). Durante a expedição de campo realizada em março, registrou-se nos recifes das ilhas de Tinharé e Boipeba, percentuais de colônias com sinais de branqueamento variando entre 7 e $17 \%$. Nos recifes do arco costeiro de Abrolhos estes percentuais variaram entre 2,5 e 8\%. Nos recifes das ilhas do Arquipélago de Abrolhos os percentuais de colônias branqueadas variaram entre 3,5 e 6,5\%, e nos chapeirões do Parcel dos Abrolhos foi registrada uma média de 7,5\% de colônias com sinais de branqueamento (Figura 3d).

2003 - Anomalias térmicas atingiram toda a costa da Bahia entre os meses de fevereiro e abril de 2003. A partir do dia 15 de fevereiro já havia registro de hot spot de $0,25^{\circ} \mathrm{C}$ na região de Abrolhos. Anomalias de $1{ }^{\circ} \mathrm{C}$ ocorreram em datas alternadas em Abrolhos até o final do mês de março e, ainda, no final de março e início de abril em Tinharé e Boipeba e no Litoral Norte. Nas demais regiões ocorreram anomalias de até $0,75^{\circ} \mathrm{C}$ (Figura $4 \mathrm{a}$ ). Nos três recifes visitados em Abrolhos em março foram registrados percentuais de colônias branqueadas variando entre 8,5 e 17,5\%. Nos recifes das ilhas de Tinharé e Boipeba, no mês de abril, os percentuais de colônias com sinais de branqueamento variaram entre 29 e $39 \%$ (Figura 5a). Na Baía de Todos os Santos foram realizadas três estimativas, duas no final do mês de abril e uma no mês de maio, quando as anomalias da temperatura alcançaram valores de $0,75^{\circ} \mathrm{C}$. Nas três ocasiões a média percentual da superfície das colônias com sinais de branqueamento, avaliada pela técnica do vídeo-transécto, atingiu valores entre 49 e $75 \%$ (Figura 5b).

2004 - A partir de fevereiro até o início de abril foram observadas anomalias térmicas de no máximo $0,25^{\circ} \mathrm{C}$ ao longo da costa do Estado da Bahia (Figura 4b). Durante excursão realizada em março nas ilhas de Tinharé e Boipeba, foram avaliados três recifes aplicandose a técnica do vídeo-transécto, quando se registrou colônias de corais com percentuais da superfície branqueada variando entre 5 e $14 \%$. Em um recife nas proximidades da Baía de Camamu este percentual alcançou o valor de 20\% (Figura 5c). Na região de Cabrália, no mês de setembro, foram investigados seis recifes onde não foram registrados corais branqueados.

2005 - Os primeiros sinais de anomalias térmicas na Bahia foram observados no início de março, em Abrolhos, e a partir daí ocorreram hot spots em toda a costa do estado, sendo que em Abrolhos alcança-
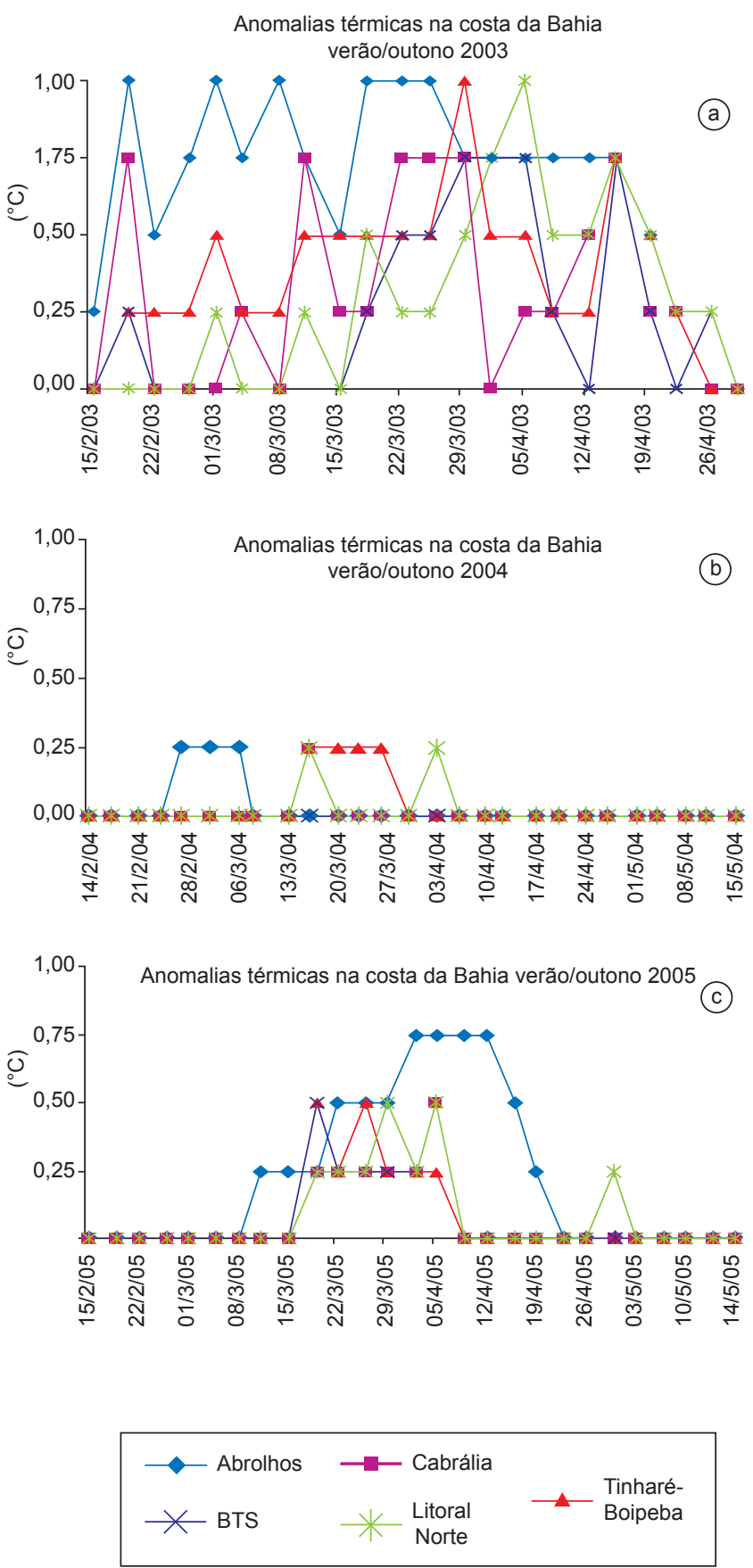

Figura 4. a) Anomalias da temperatura das águas superficiais oceânicas para a costa do Estado da Bahia, obtidas de imagens orbitais. Fonte: http://www.osdpd.noaa.gov/PSB/EPS/SST/climohot.html; 2003; b) 2004; e c) 2005 .

Figure 4. a) Sea surface temperature anomalies for the coast of the state of Bahia, taken from orbital images. Source: http://www.osdpd.noaa.gov/PSB/ EPS/SST/climohot.html; 2003; b) 2004; and c) 2005.

ram valores máximos de $0,75^{\circ} \mathrm{C}$ em abril (Figura 4c). Ainda no mês de abril nos recifes dos Itacolomis, localizados cerca de $60 \mathrm{~km}$ ao norte de Abrolhos, os percentuais de colônias de corais com sinais de branqueamento variaram entre 5 e 16,5\%. Nos recifes franjantes das ilhas de Abrolhos a média de colônias com sinais de branqueamento atingiu valores acima de $20 \%$ no início de maio (Figura 5d). 

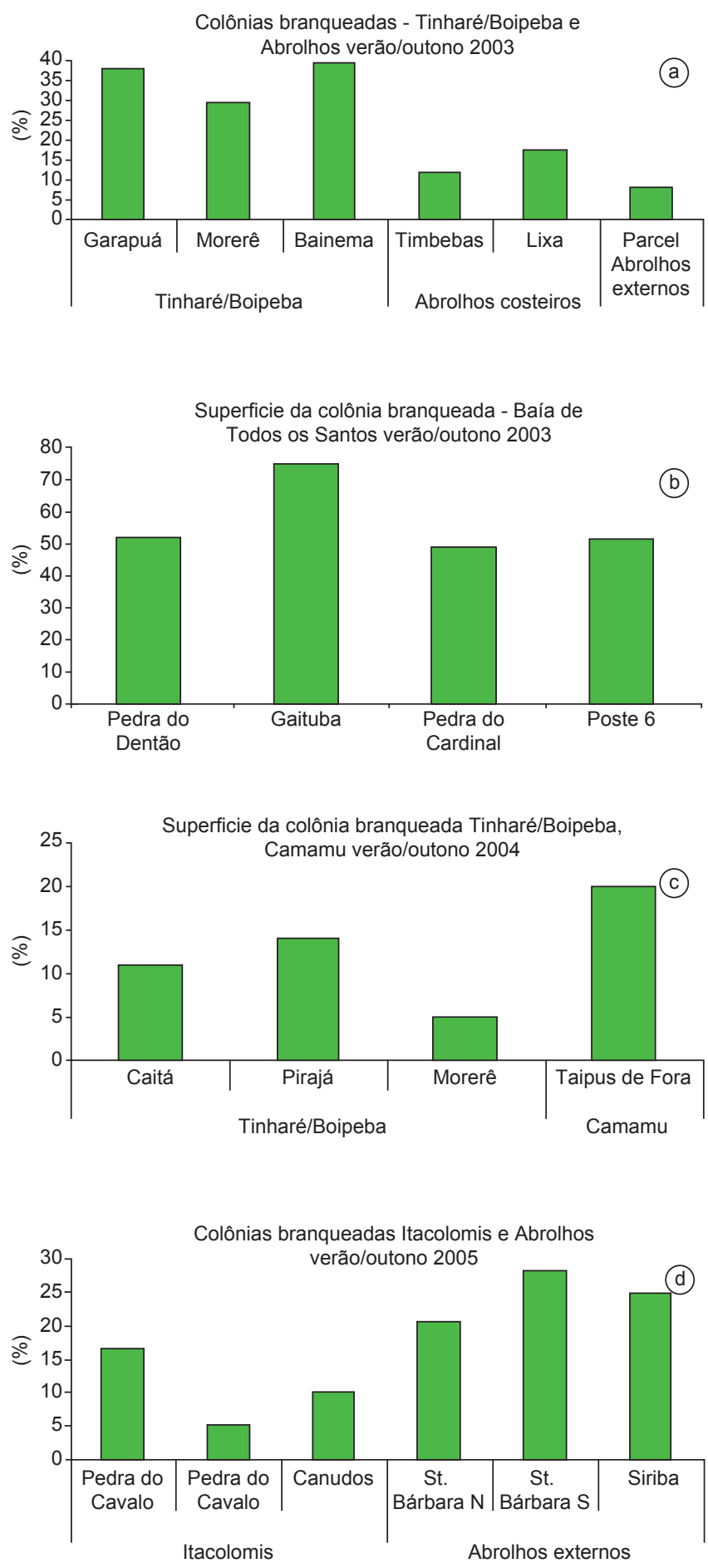

Figura 5. a,d) Branqueamento de corais expresso em termos de porcentagem de colônias afetadas; e b,c) porcentagem de superfície branqueada. 2003 recifes das ilhas de Tinharé e Boipeba (abril) e recifes costeiros e externos de Abrolhos (março); b) 2003 - recifes da Baía de Todos os Santos (abril e maio). c) 2004 - recifes das ilhas de Tinharé e Boipeba e da Baía de Camamu (fevereiro); e d) 2005 - recifes dos Itacolomis (abril) e das ilhas St. Bárbara e Siriba no Arquipélago dos Abrolhos (abril).

Figure 5. a,d) Coral bleaching expressed in percentage of affected colonies and percentage of bleached surface; and b,c) 2003 - Tinharé and Boipeba Islands reefs (April) and Abrolhos coastal and offshore reefs (March); b) 2003 - Todos os Santos Bay reefs (April and May); c) 2004 - reefs from Tinharé and Boipeba Islands and Camamu Bay (February); and d) 2005 - reefs from Itacolomis (April) and St. Barbara and Siriba Islands in the Abrolhos Archipelago (April).
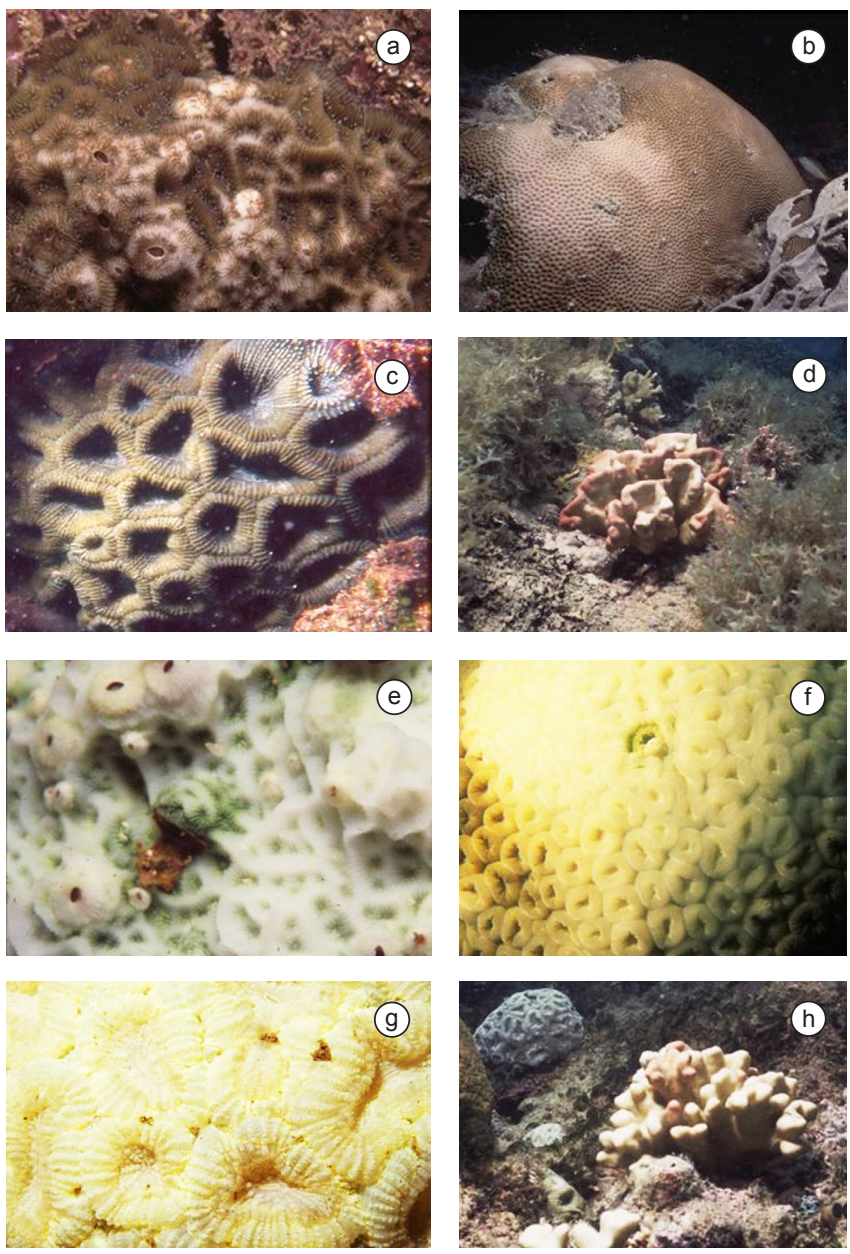

Figura 6. a-d) Branqueamento fraco; e e-h) Branqueamento forte; a) Agaricia agaricites; b) Siderastrea spp.; c) Mussismilia hispida; d) Millepora braziliensis; e) Agaricia agaricites; f) Montastraea cavernosa; g) Mussismilia hispida; e h) Millepora nitida (frente), Mussismilia hispida (fundo).

Figure 6. a-d) Light bleaching; e e-h) Heavy bleaching; a) Agaricia agaricites; b) Siderastrea spp.; c) Mussismilia hispida; d) Millepora braziliensis; e) Agaricia agaricites; f) Montastraea cavernosa; g) Mussismilia hispida; and h) Millepora nitida (front), Mussismilia hispida (back).

\section{As espécies de coral e de milepora afetadas pelo branqueamento}

Em todos os recifes investigados foi registrado branqueamento em onze espécies de corais zooxantelados: Mussismilia braziliensis, M. hispida, M. harttii, Siderastrea spp., Montastraea cavernosa, Porites astreoides, P. branneri, Favia gravida, F. leptophylla, Agaricia agaricites e Madracis decactis, e nas três espécies de mileporas: Millepora alcicornis, M. nitida e M. braziliensis. As espécies com abundância relativa $<0,5 \%$ foram consideradas "raras" de acordo com Margalef (1989) e são elas: Porites branneri, Favia gravida, Madracis decactis, Millepora nitida e Millepora braziliensis. Das 10511 colônias contadas nos recifes investigados, apenas 1273 foram afetadas por branqueamento (12\%), e os percentuais de colônias afetadas variaram entre 3 e 79\%. Excetuando as espécies "raras", em apenas cinco espécies o percentual de branqueamento atingiu valores acima de $10 \%$ (Tabela 1 ).

Entre as colônias branqueadas, 10 espécies de coral e duas de milepora apresentaram branqueamento do tipo "Forte", com valores 
Tabela 1. Número total de colônias, abundância relativa e percentual de branqueamento das espécies de coral e de milepora identificadas nos recifes da Bahia durante levantamentos realizados entre 1998 e 2005, de acordo com a metodologia do protocolo AGRRA (Atlantic and Gulf Rapid Reef Assessment) para quantificar branqueamento. Branqueamento Forte = área afetada branca; Branqueamento Fraco = área afetada pálida. Números em negrito $=\%$ colônias branqueadas $>10 \%$, não considerando espécies raras* (abundância relativa $<0,5 \%$ ).

Table 1. Number, relative abundance and bleaching percentage of identified coral and millepore species from reefs of Bahia, during surveys performed from 1998 to 2005, according to the AGRRA (Atlantic and Gulf Rapid Reef Assessment) methodology for quantifying coral bleaching. Heavy bleaching = affected area white; Light bleaching $=$ affected area pale. Bold numbers $=$ Bleached colonies $>10 \%$, not considering rare species $*$ (relative abundance $<0.5 \%$ ).

\begin{tabular}{|c|c|c|c|c|c|c|c|c|}
\hline \multirow[t]{2}{*}{ Espécies } & \multicolumn{2}{|c|}{$\begin{array}{c}\text { Colônias } \\
\text { identificadas }\end{array}$} & \multicolumn{2}{|c|}{$\begin{array}{c}\text { Colônias } \\
\text { branqueadas }\end{array}$} & \multicolumn{2}{|c|}{$\begin{array}{c}\text { Branqueamento } \\
\text { forte }\end{array}$} & \multicolumn{2}{|c|}{$\begin{array}{c}\text { Branqueamento } \\
\text { fraco }\end{array}$} \\
\hline & (\#) & $(\%)$ & $(\#)$ & $(\%)$ & (\#) & $(\%)$ & (\#) & $(\%)$ \\
\hline Mussismilia braziliensis & 4904 & 46,7 & 153 & 3 & 36 & 1 & 121 & 2 \\
\hline Mussismilia hispida & 759 & 7,2 & 270 & 35 & 90 & 12 & 173 & 23 \\
\hline Mussismilia harttii & 1112 & 10,6 & 34 & 3 & 10 & 1 & 21 & 2 \\
\hline Siderastrea spp. & 1148 & 10,9 & 443 & 39 & 92 & 8 & 356 & 31 \\
\hline Montastraea cavernosa & 774 & 7,4 & 95 & 12 & 6 & 1 & 84 & 11 \\
\hline Porites astreoides & 157 & 1,5 & 14 & 10 & 5 & 3 & 11 & 7 \\
\hline Porites branneri* ${ }^{*}$ & 35 & 0,4 & 12 & 36 & 6 & 18 & 6 & 18 \\
\hline Favia gravida* & 30 & 0,3 & 15 & 47 & 5 & 17 & 9 & 30 \\
\hline Favia leptophylla & 120 & 1,1 & 4 & 3 & 0 & 0 & 4 & 3 \\
\hline Agaricia agaricites & 199 & 1,8 & 159 & 79 & 138 & 69 & 21 & 10 \\
\hline Madracis decactis* & 2 & 0,01 & 1 & 50 & 1 & 50 & 0 & 0 \\
\hline Millepora alcicornis & 1250 & 11,8 & 68 & 6 & 25 & 2 & 48 & 4 \\
\hline Millepora nitida* & 9 & 0,1 & 3 & 33 & 1 & 10 & 2 & 20 \\
\hline Millepora braziliensis* & 12 & 0,1 & 2 & 17 & 0 & 0 & 2 & 17 \\
\hline Totais & 10511 & 100 & 1273 & $12 \%$ & 415 & $4 \%$ & 858 & $8 \%$ \\
\hline
\end{tabular}

entre 1 e 69\%. Entre as espécies consideradas raras (abundância relativa $<0,5 \%$ ), nas três de coral e em uma de milepora o branqueamento atingiu valores acima de $10 \%$. Das 13 espécies mais freqüentes (corais e mileporas) que apresentaram branqueamento "Fraco" (entre 2 e 31\%), quatro espécies apresentaram percentuais de colônias branqueadas acima de $10 \%$. Chama-se a atenção para o fato de que entre as espécies "raras" que tiveram mais de $10 \%$ das suas colônias afetadas, salientam-se as espécies Porites branneri e Favia gravida que ocorreram em maior freqüência nos recifes do Litoral Norte (Tabela 1).

Os maiores percentuais de colônias branqueadas foram observados nos recifes do Litoral Norte do estado (LN 62\%) e das ilhas de Tinharé e Boipeba (T/B 25\%) (Tabela 2) nos anos de 1998 (62\%) e 2003 (33\%), e em menor proporção no ano de 2005 (18\%) (Tabela 3) durante eventos de anomalias térmicas mais elevadas.

Mussismilia braziliensis - esta espécie apresentou o maior número de colônias avaliadas (4904) com percentual de colônias branqueadas de apenas $3 \%$, sendo $1 \%$ de branqueamento do tipo "Forte" (Tabela 1). Nos recifes de Abrolhos onde esta espécie apresentou a maior ocorrência (>4000 colônias), o branqueamento não atingiu mais de 3\% das colônias, porém nos recifes dos Itacolomis e das ilhas de Tinharé e Boipeba o percentual de colônias afetadas variou entre 10 e $24 \%$, respectivamente (Tabela 2). Os percentuais mais altos de branqueamento em $M$. braziliensis ocorreram durante os eventos de anomalias térmicas dos anos de 2003 (16\%) e 2005 (18\%) (Tabela 3).

Mussismilia hispida - esta espécie ocupa o sexto lugar entre as espécies que apresentaram mais de 100 colônias avaliadas, e é a segunda no percentual de colônias branqueadas (35\%), sendo $12 \%$ de branqueamento do tipo "Forte" e $23 \%$ do tipo "Fraco" (Tabela 1).
Ela foi abundante nos recifes do Litoral Norte e das ilhas de Tinharé e Boipeba onde o número de colônias contadas foi superior a 300, com teores de branqueamento variando entre 56 e $16 \%$ respectivamente (Tabela 2). Os maiores percentuais de colônias branqueadas desta espécie foram observados durante os eventos que ocorreram nos anos de 1998 no Litoral Norte (56\%) e de 2003 nas ilhas de Tinharé e Boipeba (35\%) (Tabela 3).

Mussismilia harttii - esta espécie ocupa o quarto lugar no número de colônias avaliadas (1112), porém com percentual de colônias branqueadas de $3 \%$ (Tabela 1). O maior número de colônias foi observado nos recifes de Abrolhos (>900 colônias), nos recifes dos Itacolomis foram contadas 71 colônias e nos recifes das ilhas de Tinharé e Boipeba foram registradas apenas 17 colônias. Esta espécie não foi observada durante inspeção realizada nos recifes do Litoral Norte (Tabela 2). Percentual acima de $10 \%$ de colônias branqueadas ocorreu em 2005 nos recifes dos Itacolomis e das ilhas do Arquipélago dos Abrolhos (Tabela 3).

Siderastrea spp. - as colônias dos corais pertencentes ao complexo Siderastrea (este coral não foi identificado no campo em nível de espécie) ocupam a terceira colocação em número de colônias investigadas (1148) e a segunda em percentual de colônias branqueadas (39\%), com a maioria do tipo branqueamento "Fraco" (31\%) (Tabela 1). Elas foram observadas em todos os recifes investigados com números variando entre o mínimo de 16 (Itacolomis) e o máximo de 478 (Litoral Norte) e percentuais de colônias branqueadas entre $8 \%$ nos recifes do arco costeiro de Abrolhos e 65\% no Litoral Norte (Tabela 2). Os maiores percentuais de branqueamento ocorreram durante eventos de anomalias térmicas dos anos de 1998 (65\%) e 2003 (81\%) (Tabela 3). 
Tabela 2. Número total de colônias investigadas e percentual de colônias branqueadas das espécies de coral e de milepora identificadas em cada recife da Bahia durante levantamentos realizados entre 1998 e 2005. LN = Litoral Norte (1998); T/B = Tinharé e Boipeba (2002 - 2003); ITA = Itacolomis (2005); $\mathrm{ABC}=$ Abrolhos recifes costeiros (2001 a 2003); ABA = Abrolhos recifes do Arquipélago (2000 a 2005); PAB = Parcel dos Abrolhos (2000 a 2003). Números em negrito $=$ branqueamento $>10 \%$, não considerando espécies raras* (abundância relativa $<0,5 \%$ ).

Table 2. Number of investigated coral colonies and bleaching percentage of identified coral and millepore species in every reef of Bahia, during surveys performed from 1998 to 2005. LN = Litoral Norte (1998); T/B = Tinharé and Boipeba (2002 - 2003); ITA = Itacolomis (2005); ABC = Abrolhos coastal reefs (2001 a 2003); $\mathrm{ABA}=$ Abrolhos reefs from the Arquipélago (2000 a 2005); PAB = Parcel of Abrolhos (2000 a 2003). Bold numbers $=$ Bleached colonies $>$ $10 \%$, not considering rare species* (relative abundance $<0.5 \%$ ).

\begin{tabular}{|c|c|c|c|c|c|c|c|c|c|c|c|c|}
\hline \multirow[t]{2}{*}{ Espécies } & \multicolumn{2}{|c|}{$\mathbf{L N}$} & \multicolumn{2}{|c|}{$\mathbf{T} / \mathbf{B}$} & \multicolumn{2}{|c|}{ ITA } & \multicolumn{2}{|c|}{$\mathrm{ABC}$} & \multicolumn{2}{|c|}{$\mathbf{A B A}$} & \multicolumn{2}{|c|}{ PAB } \\
\hline & $\begin{array}{c}\text { Total } \\
(\#)\end{array}$ & $\begin{array}{c}\text { Branq } \\
(\%)\end{array}$ & $\begin{array}{c}\text { Total } \\
(\#)\end{array}$ & $\begin{array}{c}\text { Branq } \\
(\%)\end{array}$ & $\begin{array}{c}\text { Total } \\
(\#)\end{array}$ & $\begin{array}{c}\text { Branq } \\
(\%)\end{array}$ & $\begin{array}{c}\text { Total } \\
(\#)\end{array}$ & $\begin{array}{c}\text { Branq } \\
(\%)\end{array}$ & $\begin{array}{c}\text { Total } \\
(\#)\end{array}$ & $\begin{array}{c}\text { Branq } \\
(\%)\end{array}$ & $\begin{array}{c}\text { Total } \\
(\#)\end{array}$ & $\begin{array}{c}\text { Branq } \\
(\%)\end{array}$ \\
\hline Mussismilia braziliensis & 0 & 0 & 92 & 24 & 23 & 10 & 1250 & 2 & 2235 & 3 & 1304 & 3 \\
\hline Mussismilia hispida & 342 & 56 & 396 & 16 & 4 & 25 & 7 & 0 & 3 & 0 & 7 & 0 \\
\hline Mussismilia harttii & 0 & 0 & 17 & 20 & 71 & 6 & 839 & 1 & 50 & 14 & 135 & 7 \\
\hline Siderastrea spp. & 478 & 65 & 99 & 58 & 16 & 20 & 292 & 8 & 77 & 21 & 186 & 20 \\
\hline Montastraea cavernosa & 52 & 8 & 12 & 8 & 21 & 29 & 499 & 11 & 118 & 10 & 72 & 18 \\
\hline Porites astreoides & 0 & 0 & 33 & 15 & 12 & 8 & 28 & 0 & 17 & 6 & 67 & 13 \\
\hline Porites branneri* & 12 & 66 & 12 & 33 & 0 & 0 & 2 & 0 & 0 & 0 & 9 & 0 \\
\hline Favia gravida* & 29 & 45 & 1 & 100 & 0 & 0 & 0 & 0 & 0 & 0 & 0 & 0 \\
\hline Favia leptophylla & 0 & 0 & 0 & 0 & 3 & 0 & 67 & 3 & 31 & 0 & 19 & 10 \\
\hline Agaricia agaricites & 195 & 79 & 4 & 80 & 0 & 0 & 0 & 0 & 0 & 0 & 0 & 0 \\
\hline Madracis decactis* & 0 & 0 & 2 & 50 & 0 & 0 & 0 & 0 & 0 & 0 & 0 & 0 \\
\hline Millepora alcicornis & 0 & 0 & 11 & 36 & 128 & 6 & 845 & 5 & 74 & 14 & 192 & 3 \\
\hline Millepora nitida* & 0 & 0 & 0 & 0 & 0 & 0 & 9 & 33 & 0 & 0 & 0 & 0 \\
\hline Millepora braziliensis* & 0 & 0 & 0 & 0 & 0 & 0 & 0 & 0 & 7 & 0 & 5 & 40 \\
\hline Total de colônias branqueadas & & $62 \%$ & & $25 \%$ & & $9 \%$ & & $4 \%$ & & $4 \%$ & & $6 \%$ \\
\hline
\end{tabular}

LN = Litoral Norte (1998); T/B = Tinharé e Boipeba (2002 - 2003); ITA = Itacolomis (2005); ABC = Abrolhos recifes costeiros (2001 a 2003); ABA = Abrolhos recifes do Arquipélago (2000 a 2005); e PAB = Parcel dos Abrolhos (2000 a 2003).

LN = North Coast (1998); T/B = Tinharé and Boipeba (2002, 2003); ITA = Itacolomis (2005); ABC = Abrolhos Coastal Reefs (2001 to 2003); $\mathrm{ABA}=$ Abrolhos Archipelago Reefs (2000 to 2005); and PAB = Parcel of Abrolhos (2000 to 2003).

Tabela 3. Número total de colônias investigadas e percentual de colônias branqueadas das espécies de coral e de milepora identificadas nos recifes da Bahia nos anos de 1998 (LN); 2000 (ABA, PAB); 2001 (ABC, ABA, PAB); 2002 (T/B, ABC, ABA, PAB); 2003 (T/B, ABC, PAB); 2005 (ITA, ABA). LN = Litoral Norte; $\mathrm{T} / \mathrm{B}=$ Tinharé e Boipeba; ITA - Itacolomis; $\mathrm{ABC}=$ Abrolhos recifes costeiros; $\mathrm{ABA}=$ Abrolhos recifes do Arquipélago; PAB = Parcel dos Abrolhos Números em negrito $=$ Branqueamento $>10 \%$, não considerando espécies raras* (abundância relativa $<0,5 \%$ ).

Table 3. Number of investigated coral colonies and bleaching percentage of identified coral and millepore species from reefs of Bahia during the years of 1998 (LN); 2000 (ABA, PAB); 2001 (ABC, ABA, PAB); 2002 (T/B, ABC, ABA, PAB); 2003 (T/B, ABC, PAB); 2005 (ITA, ABA). LN = Litoral Norte; T/B = Tinharé and Boipeba; ITA - Itacolomis; $\mathrm{ABC}=$ Abrolhos coastal reefs; $\mathrm{ABA}=$ Abrolhos reefs of Arquipélago; $\mathrm{PAB}=$ Parcel of Abrolhos. Bold numbers $=\%$ bleached colonies $>10 \%$, not considering rare species* (relative abundance $<0.5 \%$ ).

\begin{tabular}{|c|c|c|c|c|c|c|c|c|c|c|c|c|}
\hline \multirow[t]{4}{*}{ Espécies } & \multirow{2}{*}{\multicolumn{2}{|c|}{$\begin{array}{c}1998 \\
\text { LN } \\
\end{array}$}} & \multicolumn{2}{|c|}{2000} & \multicolumn{2}{|c|}{2001} & \multicolumn{2}{|c|}{2002} & \multicolumn{2}{|c|}{2003} & \multicolumn{2}{|c|}{2005} \\
\hline & & & \multirow{3}{*}{$\begin{array}{c}\mathbf{A B A} \\
(\#)\end{array}$} & \multirow{3}{*}{$\frac{\text { PAB }}{(\%)}$} & $\mathbf{A B C}$ & ABA & \multirow{2}{*}{$\begin{array}{r}\text { T/B } \\
\text { ABA } \\
\end{array}$} & \multirow{3}{*}{$\begin{array}{c}\text { ABC } \\
\text { PAB } \\
(\%)\end{array}$} & T/B & $\mathrm{ABC}$ & \multirow{3}{*}{$\frac{\text { ITA }}{(\#)}$} & \multirow{3}{*}{$\frac{\text { ABA }}{(\%)}$} \\
\hline & \multirow[t]{2}{*}{ (\#) } & \multirow[t]{2}{*}{$(\%)$} & & & \multicolumn{2}{|c|}{ PAB } & & & \multicolumn{2}{|c|}{ PAB } & & \\
\hline & & & & & $(\#)$ & $(\%)$ & (\#) & & (\#) & $(\%)$ & & \\
\hline Mussismilia braziliensis & 0 & 0 & 996 & 1 & 1771 & 2 & 1640 & 2 & 147 & 16 & 350 & 18 \\
\hline Mussismilia hispida & 342 & 56 & 7 & 0 & 7 & 0 & 277 & 13 & 122 & 35 & 4 & 25 \\
\hline Mussismilia harttii & 0 & 0 & 56 & 4 & 336 & 2 & 610 & 1 & 24 & 8 & 86 & 21 \\
\hline Siderastrea spp. & 478 & 65 & 31 & 6 & 308 & 7 & 234 & 20 & 65 & 81 & 32 & 22 \\
\hline Montastraea cavernosa & 52 & 8 & 62 & 11 & 284 & 10 & 303 & 11 & 27 & 15 & 46 & 48 \\
\hline Porites astreoides & 0 & 0 & 3 & 33 & 49 & 0 & 80 & 9 & 13 & 31 & 12 & 17 \\
\hline Porites branneri* ${ }^{*}$ & 12 & 66 & 0 & 0 & 9 & 0 & 4 & 25 & 10 & 50 & 0 & 0 \\
\hline Favia gravida* & 29 & 45 & 0 & 0 & 0 & 0 & 0 & 0 & 1 & 100 & 0 & 0 \\
\hline Favia leptophylla & 0 & 0 & 25 & 8 & 34 & 3 & 53 & 2 & 0 & 0 & 8 & 0 \\
\hline Agaricia agaricites & 195 & 79 & 0 & 0 & 0 & 0 & 2 & 0 & 2 & 100 & 0 & 0 \\
\hline Madracis decactis* & 0 & 0 & 0 & 0 & 0 & 0 & 0 & 0 & 2 & 50 & 0 & 0 \\
\hline Millepora alcicornis & 0 & 0 & 77 & 4 & 409 & 6 & 563 & 3 & 62 & 27 & 139 & 6 \\
\hline Millepora nitida* & 0 & 0 & 0 & 0 & 3 & 0 & 5 & 40 & 0 & 0 & 1 & 100 \\
\hline Millepora braziliensis* & 0 & 0 & 5 & 40 & 7 & 0 & 0 & 0 & 0 & 0 & 0 & 0 \\
\hline Total de colônias branqueadas & & $62 \%$ & & $2 \%$ & & $4 \%$ & & $5 \%$ & & $33 \%$ & & $18 \%$ \\
\hline
\end{tabular}

LN = Litoral Norte; T/B = Tinharé e Boipeba; ITA = Itacolomis; ABC = Abrolhos recifes costeiros; ABA = Abrolhos recifes do Arquipélago; e $\mathrm{PAB}=$ Parcel dos Abrolhos

LN $=$ North Coast $;$ T/B $=$ Tinharé and Boipeba; ITA = Itacolomis; ABC = Abrolhos Coastal Reefs; ABA = Abrolhos Archipelago Reefs; and $\mathrm{PAB}=$ Parcel of Abrolhos. 
Montastraea cavernosa - esta espécie ocupa o quinto lugar em número de colônias avaliadas (774) com 12\% de colônias branqueadas, predominantemente do tipo branqueamento "Fraco" (Tabela 1). Ela foi encontrada em maior quantidade nos recifes do arco costeiro (499) e do arquipélago de Abrolhos (118), onde os teores de branqueamento atingiram valores de 11 e $10 \%$, respectivamente, porém o maior percentual de colônias branqueadas foi registrado nos recifes dos Itacolomis (29\%) (Tabela 2). Percentuais variados de colônias branqueadas entre 10 e $15 \%$ ocorreram nos anos de 2000 a 2003, e em 2005 o percentual de colônias branqueadas atingiu $48 \%$ nos recifes dos Itacolomis e das ilhas do Arquipélago de Abrolhos (Tabela 3).

O gênero Porites - o número de colônias avaliadas da espécie P. astreoides foi maior (157) que da espécie P. branneri (35), a qual, entretanto, foi mais fortemente afetada pelo branqueamento $(36 \%$ para P. branneri - $10 \%$ para P. astreoides) (Tabela 1). Colônias de $P$. astreoides foram registradas, à exceção dos recifes do Litoral Norte, em todos os demais recifes, com teores de colônias branqueadas variando entre $6 \%$ nos recifes do arquipélago e $15 \%$ nos recifes das ilhas de Tinharé e Boipeba. A espécie $P$. branneri, considerada espécie "rara" (abundância relativa $<0,5 \%$ ) apresentou maior número de colônias nos recifes do Litoral Norte e das ilhas de Tinharé e Boipeba, em ambas as localidades com 12 colônias, porém com teores altos de branqueamento, 66 e $33 \%$, respectivamente (Tabela 2). Os maiores percentuais de branqueamento do gênero ocorreram nos anos de 1998 (LN, 66\%) e 2003 (T/B, ABC, PAB, 81\%) (Tabela 3).

O gênero Favia - embora nos recifes investigados a espécie F. leptophylla tenha apresentado uma maior freqüência que a espécie F. gravida com 120 e 30 colônias, respectivamente, F. gravida, considerada espécie "rara", apresentou um teor muito mais elevado de colônias branqueadas, $47 \%$ contra $3 \%$ para F. leptophylla (Tabela 1). Das 30 colônias registradas de $F$. gravida, 29 ocorreram nos recifes do Litoral Norte, das quais $45 \%$ foram observadas branqueadas durante o evento de 1998. F. leptophylla apresentou um registro maior nos recifes de Abrolhos onde o maior percentual de colônias branqueadas (8\%) foi observado nos recifes do Parcel dos Abrolhos no ano de 2000 (Tabelas 2, 3).

Agaricia agaricites - é a espécie que apresentou o maior percentual de colônias branqueadas (79\%), assim como também do tipo branqueamento "Forte" (69\%) (Tabela 1, Figura 6). Ela foi registrada quase que exclusivamente nos recifes do Litoral Norte, com 79\% das colônias branqueadas durante o evento de 1998 (Tabela 2), tendo sido observadas apenas quatro colônias nos recifes das ilhas de Tinharé e Boipeba, duas em 2002 e duas branqueadas em 2003 (Tabela 3).

Madracis decactis - esta espécie "rara" apresentou a menor ocorrência registrada nos recifes investigados, com duas espécies nos recifes das ilhas de Tinharé e Boipeba e apenas uma colônia com sinal de branqueamento no ano de 2003 (Tabelas 1, 2, 3).

O gênero Millepora - a espécie Millepora alcicornis foi a segunda em número de colônias registradas (1250) nos recifes da Bahia durante a realização deste trabalho, porém com percentual de branqueamento total inferior a $10 \%$ (Tabela 1). O maior percentual de colônias branqueadas ocorreu nos recifes das ilhas de Tinharé e Boipeba (36\%), predominantemente durante o evento do ano de 2003 (27\%) (Tabelas 2, 3). As outras duas espécies M. nitida e M. braziliensis, classificadas como "raras", só foram registradas nos recifes de Abrolhos, sendo nove colônias de $M$. nítida e 12 colônias de M. braziliensis (Tabelas 1,2). Apenas três colônias de $M$. nítida (33\%) foram observadas branqueadas, duas em 2002 e uma em 2005. Das 12 colônias de M. braziliensis, apenas duas (40\%) estavam branqueadas nos recifes do Parcel dos Abrolhos no ano de 2000 (Tabelas 2, 3).

\section{Discussão}

Eventos de branqueamento de corais nos recifes do estado da Bahia registrados anteriormente a este trabalho ocorreram desde o verão de 1993/1994, e estiveram associados com a ocorrência de eventos El-Niño (Castro \& Pires 1999, Leão et al. 1999, Dutra et al. 2000). Os eventos estudados durante a realização deste trabalho apontam, também, para a relação do fenômeno com a ocorrência de anomalias térmicas das águas superficiais do oceano. Todos os eventos relatados foram investigados nas áreas de maior ocorrência de recifes de coral da costa do estado da Bahia, descritas em Leão et al. (2003), quais sejam: o Litoral Norte do estado, a Baía de Todos os Santos, a região das ilhas de Tinharé e Boipeba e baía de Camamu, a região de Cabrália/Porto-Seguro, os recifes dos Itacolomis, em Corumbau, e a região de Abrolhos. Para todas estas regiões, foi verificado se havia relação entre a ocorrência de anomalias térmicas e o branqueamento de corais nos anos de 1998 a 2005. Os trabalhos de campo foram realizados sempre após algumas semanas do início da ocorrência da anomalia, para que se pudesse registrar a presença de corais já branqueados, considerando que o branqueamento comumente surge algumas semanas após o início da anomalia térmica (Goreau \& Hayes 1994). No recife das Caramuanas, contudo, isto não ocorreu, pois o registro foi realizado seis meses após a ocorrência da anomalia térmica.

A ocorrência de branqueamento nos corais foi registrada em todas as regiões investigadas, exceto na região de Cabrália. No ano de investigação dos recifes de Cabrália (2004) a anomalia térmica observada na região foi de $0,25{ }^{\circ} \mathrm{C}$, durante apenas uma semana (entre $13 \mathrm{e}$ 20 de março) (Figura 4b), período que foi considerado insuficiente para causar branqueamento de coral nos recifes estudados.

Desde o final de janeiro até o início de maio de 1998, quando as anomalias térmicas no Litoral Norte da Bahia e na cidade de Salvador permaneceram iguais ou maiores que $0,5^{\circ} \mathrm{C}$, por 13 semanas, e atingindo $1{ }^{\circ} \mathrm{C}$ durante duas semanas, o percentual de colônias de corais branqueadas ultrapassou de $50 \%$ no Litoral Norte. Nos recifes das Caramuanas, na Baía de Todos os Santos, cerca de 20\% dos corais apresentaram sinais de branqueamento ainda em outubro daquele ano. Este percentual mais baixo nos recifes das Caramuanas pode não representar o efeito que o aumento da temperatura da superfície do mar causou nos corais, pois a avaliação foi realizada seis meses após a ocorrência das anomalias térmicas (hot spots) para o norte da Bahia, um período provavelmente suficiente para que algumas espécies de coral já tivessem recuperado. Este fato coincide com o relato de Dutra et al. (2000) que aponta que o período de recuperação das espécies de coral do Litoral Norte ocorreu de seis a oito meses após o branqueamento, ligado à ocorrência do fenômeno El-Niño de 1997/1998 que causou a morte de aproximadamente 16\% dos recifes de corais do mundo, particularmente dos oceanos Índico e Pacífico (Wilkinson \& Souter 2008).

Uma anomalia térmica de $0,25^{\circ} \mathrm{C}$, em 2000 , ocorreu na região de Abrolhos durante duas semanas alternadas, causando branqueamento em menos de $5 \%$ dos corais dos recifes em franja que bordejam as ilhas do arquipélago. Em 2002 na região das ilhas de Tinharé e Boipeba, uma anomalia de também $0,25^{\circ} \mathrm{C}$ por duas semanas alternadas, causou branqueamento atingindo uma média de $12 \%$ dos corais nas quatro localidades inspecionadas. Em 2004, nesta mesma região, uma outra anomalia de $0,25^{\circ} \mathrm{C}$, por duas semanas seguidas, provocou branqueamento dos corais cujo percentual da superfície das colônias afetadas alcançou 14\% nos recifes de Tinharé e Boipeba e 20\% nos recifes de Camamu. Estas observações sugerem que anomalias de $0,25{ }^{\circ} \mathrm{C}$, por duas semanas, podem causar branqueamento dos corais dos recifes rasos localizados muito próximos $(<5 \mathrm{~km})$ ou adjacentes à costa, com teores de até $20 \%$ da superfície das colônias atingidas. 
Entretanto, este tipo de evento não causou níveis de branqueamento elevados nos corais dos recifes das ilhas do arquipélago dos Abrolhos que, embora também rasos, estão localizados a uma maior distância da costa $(>50 \mathrm{~km})$.

Anomalias térmicas entre 0,50 e $0,75{ }^{\circ} \mathrm{C}$ ocorreram em 2001 e 2002 em Abrolhos com duração não superior a uma semana, quando foi observado menos de $10 \%$ de colônias branqueadas. Em 2005 anomalias dentro desta mesma categoria, porém com duração de duas a três semanas causou branqueamento em mais de $20 \%$ dos corais dos recifes das ilhas do arquipélago, avaliados no mês de maio. Este fato indica que a associação entre o aumento da temperatura e a duração da anomalia foi a causa principal do aumento da frequiência do branqueamento de corais nesta região (Rodriguez-Ramirez et al. 2008). Embora não se tenha observado branqueamento extensivo em 2005 nos demais recifes da Bahia, este foi um ano considerado muito quente no hemisfério norte (Caribe e Atlântico), onde o branqueamento afetou de 50 a $90 \%$ das colônias dos corais (Wilkinson \& Souter 2008).

Anomalias térmicas acima de $0,75^{\circ} \mathrm{C}$ com duração de mais de uma semana, foram observadas em 2003 no Litoral Norte, na Baía de Todos os Santos, nas ilhas de Tinharé e Boipeba e na região de Abrolhos, causando branqueamento nos recifes investigados ao longo de uma extensão de quase $1.000 \mathrm{~km}$. Mais uma vez os recifes rasos, localizados próximos e/ou adjacentes à costa foram os mais atingidos pelo branqueamento. Nas ilhas de Tinharé e Boipeba mais de $30 \%$ dos corais branquearam, nos recifes da Baía de Todos os Santos os corais tiveram mais de $50 \%$ da superfície de suas colônias branqueadas, enquanto que nos recifes de Abrolhos o percentual de colônias branqueadas variou entre 8 e $18 \%$.

A relação entre as ocorrências de branqueamento nos recifes de corais da Bahia com os eventos de anomalias térmicas, entre 1998 e 2005 , mostra que anomalias de $0,25^{\circ} \mathrm{C}$, com duração de mais de uma semana, causaram branqueamento acima de $10 \%$ nos recifes localizados muito próximos $(<5 \mathrm{~km})$ ou adjacentes à costa, e que durante eventos de anomalias superiores a $0,50{ }^{\circ} \mathrm{C}$, com mesma duração, o percentual de colônias branqueadas, nestes recifes, atingiu valores acima de $30 \%$. Na região de Abrolhos, onde os recifes estão localizados distantes da costa $(>10 \mathrm{~km})$, percentuais de branqueamento acima de $10 \%$ só ocorreram durante eventos de anomalias térmicas acima de $0,50{ }^{\circ} \mathrm{C}$ com duração de mais de duas semanas.

Os eventos mais fortes de branqueamento, anteriores e durante este trabalho, ocorreram durante os anos de 1993, de 1998 e de 2003, quando a temperatura da água registrou temperaturas elevadas coincidindo com a ocorrência de eventos El-Niño (http://ciram. epagri.rct-sc.br).

Medidas in situ da temperatura da água superficial na região do Litoral Norte, realizadas por Dutra (2000) durante o ano de 1998, indicam temperaturas máximas de 29,5 e $30,5^{\circ} \mathrm{C}$ nos dias 14 e 17 de abril, respectivamente, quando houve indicação de anomalias térmicas de $0,50{ }^{\circ} \mathrm{C}$, após um período de anomalias de $1{ }^{\circ} \mathrm{C}$ (ver figura $2 \mathrm{a}$ ).

Para a região de Abrolhos, dados da temperatura da água para os últimos 30 anos, obtidos junto ao BNDO (Banco Nacional de Dados Oceanográficos) da DHN (Diretoria de Hidrografia e Navegação) mostram que as médias das temperaturas máximas de dezembro a maio de 1993, 1998 e 2003, alcançaram 26,7, 28,2 e 26,3 ${ }^{\circ} \mathrm{C}$, respectivamente, e as temperaturas máximas de janeiro a abril de 1993 , 1998 e 2003, alcançaram $27,28,7$ e $26,5^{\circ} \mathrm{C}$, respectivamente (ver Figura 7). Apesar de terem sido registradas anomalias de $1{ }^{\circ} \mathrm{C}$ com duração de mais de uma semana na região de Abrolhos em 2003, a temperatura máxima de janeiro a abril nesta região medida in situ foi de $26,5^{\circ} \mathrm{C}$, ou seja, $0,8^{\circ} \mathrm{C}$ acima da média climatológica, que é de $25,7^{\circ} \mathrm{C}$ nos últimos 30 anos em Abrolhos (1974-2005) (ver Figura 7). $\mathrm{O}$ fato de não ter ocorrido um aumento no percentual de colônias
Temperatura da água de Abrolhos
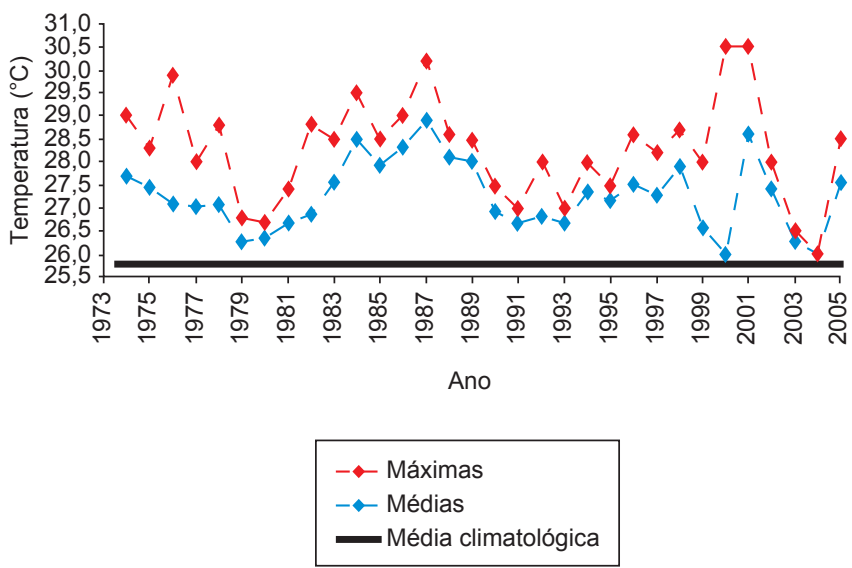

Figura 7. Dados da temperatura da superfície da água do mar $\left({ }^{\circ} \mathrm{C}\right)$ da região de Abrolhos para os últimos 30 anos, obtidos junto ao BNDO (Banco Nacional de Dados Oceanográficos) da DHN (Diretoria de Hidrografia e Navegação) do Ministério da Marinha do Brasil. Linha em vermelho indica as temperaturas máximas de janeiro a abril, linha em azul indica as temperaturas médias das máximas de dezembro a maio e linha em preto indica a média climatológica de 30 anos.

Figure 7. Sea surface temperature $\left({ }^{\circ} \mathrm{C}\right)$ from the Abrolhos region during the last 30 years (source: National Oceanographic Database of the Hidrography and Navigation Directory of the Brazilian Navy). Red line indicates maximum temperatures from January to April, blue line indicates the mean of maximum temperatures from December to May, and black line indicates the 30 years climatology mean.

branqueadas na região de Abrolhos (Abrolhos externo) no ano de 2003, como foi verificado nos recifes de Tinharé-Boipeba, pode ser devido à temperatura da água local de Abrolhos que não ultrapassou de $26,5^{\circ} \mathrm{C}$, a qual não foi suficiente para disparar o branqueamento dos corais mesmo com anomalias de $1{ }^{\circ} \mathrm{C}$ persistindo por mais de uma semana.

Em 2005 as médias das temperaturas máximas de dezembro a maio obtidas in situ alcançaram $27,5^{\circ} \mathrm{C}$, e a temperatura máxima de janeiro a abril alcançou $28,5^{\circ} \mathrm{C}$, ou seja, $2,8{ }^{\circ} \mathrm{C}$ acima da media climatológica nos últimos 30 anos em Abrolhos (25,7 $\left.{ }^{\circ} \mathrm{C}, 1974-2005\right)$ levando ao dobro do percentual de colônias branqueadas em relação ao ano de 2002, quando a média das temperaturas máximas de dezembro a maio alcançou $27,8{ }^{\circ} \mathrm{C}$ e a máxima de janeiro a abril alcançou $28{ }^{\circ} \mathrm{C}$ (ver Figura 7). Apesar das medidas de temperaturas (médias e máximas) nos anos de 2002 e 2005 apresentarem valores semelhantes, provavelmente o aumento do percentual de colônias branqueadas em 2005 deve-se à persistência da anomalia de temperatura por mais de uma semana.

Nos recifes investigados observou-se, também, que algumas espécies de corais apresentaram-se mais afetadas que outras, tanto no percentual de colônias branqueadas como no grau de branqueamento, se forte ou fraco. E estes percentuais variaram dentro de um mesmo recife, em recifes localizados na mesma região e/ou em áreas recifais diferentes. Por exemplo, a espécie Mussismilia braziliensis, a mais abundante durante as inspeções realizadas, apresentou baixa freqüência de colônias branqueadas nos recifes da região de Abrolhos $(<3 \%)$, enquanto que nos recifes da ilhas de Tinharé e Boipeba o percentual de colônias branqueadas desta espécie alcançou $24 \%$. As espécies do complexo Siderastrea apresentaram comportamento semelhante, estavam presentes em todos os recifes investigados e os percentuais de colônias branqueadas foram muito maiores nos recifes do Litoral Norte e das ilhas de Tinharé e Boipeba (>50\%) 
que nos demais recifes $(<20 \%)$. Espécies menos freqüentes como Porites branneri e Agaricia agaricites, apresentaram teores mais altos de colônias branqueadas ( $>35$ e $75 \%$, respectivamente) que as espécies mais abundantes.

Todos estes dados mostram que os eventos de maior ocorrência de colônias branqueadas e de maior número de espécies de corais afetadas, de 1998 a 2005 na costa da Bahia, estão fortemente relacionados com eventos de anomalias térmicas das águas superficiais do mar, e que os recifes que mostraram o maior percentual de corais afetados por branqueamento são os do Litoral Norte e das ilhas de Tinharé e Boipeba. Estes recifes estão localizados mais próximos da costa e, consequentemente, mais expostos aos efeitos dos impactos provenientes de processos que ocorrem na região costeira sob influência da atividade humana, a exemplo dos níveis elevados de nutrientes e das altas taxas de sedimentação. Levantamentos dos parâmetros indicadores das condições vitais dos recifes da Bahia, especificamente a taxa de cobertura de corais vivos, a densidade das colônias maiores que $20 \mathrm{~cm}$, a densidade dos recrutas de corais e o percentual de morte recente nos corais construtores, evidenciam a deterioração dos recifes costeiros em relação aos recifes localizados mais distantes da costa (Kikuchi et al. 2008) (Figura 8). Esta condição de estresse dos recifes costeiros pode estar tornando-os mais susceptíveis ao branqueamento. Exemplos da literatura mostram que o grau de impacto do aquecimento das águas sobre os recifes depende da extensão de degradação a que eles já se apresentam, como em vários recifes da Jamaica e da Flórida, que devido ao estado de deterioração em conseqüência dos efeitos de ações de origem antropogênica, foram fortemente afetados durante eventos sucessivos de branqueamento (Hughes et al. 2003, Goldberg \& Wilkinson 2004). Em longo prazo, a recuperação destes recifes expostos a vários tipos de estressores ambientais vai depender tanto do grau de aclimatação e/ou adaptação dos corais às novas temperaturas como, também, à frequiência dos distúrbios (MacField et al. 2008).

Embora os percentuais de colônias branqueadas nos recifes costeiros da Bahia em alguns casos tenham sido relativamente altos ( $>50 \%$ ), até o momento não foi observada mortalidade em massa desses corais. Seria isto uma indicação de que algumas espécies de corais dos recifes brasileiros já estejam adaptadas a estas variações ambientais? Segundo registros da literatura há espécies de coral que branqueiam e morrem em resposta ao aquecimento da água e há outras espécies que branqueiam e sobrevivem (McClanaham 2004). Para aquelas que sobrevivem ao branqueamento, as variações da temperatura da água do mar podem se tornar um potencial para sua aclimatação ou adaptação e, assim, elas irão apresentar uma maior resistência ao atual cenário de aquecimento da água superficial dos oceanos. Já para aquelas que apresentam uma maior susceptibilidade às variações da temperatura da água e têm ocorrência mais baixa, pode aumentar a chance de sua extinção regional (McClanaham et al. 2007). No caso dos recifes estudados as espécies mais afetadas pelo branqueamento foram aquelas mais comuns nos recifes costeiros, onde os corais têm sobrevivido a episódios de branqueamento mais forte. Segundo observações de Causey (2008), as espécies que já estão adaptadas a uma maior variação das condições ambientais, porque estão normalmente mais expostas a níveis elevados de nutrientes e a variações sazonais mais altas da temperatura da água, podem já estar mais resistentes aos efeitos do pós branqueamento, por exemplo doenças infecciosas e mortalidade em massa.

Nos recifes de Abrolhos, onde a espécie Mussismilia braziliensis tem uma freqüência alta, porém o nível de branqueamento tem sido mais baixo, a partir de 2005 foi observada a ocorrência de corais desta espécie apresentando sinais de doenças infecciosas (Francini-Filho et al. 2008). Este fato merece atenção considerando que embora o grau de branqueamento observado em Abrolhos tenha

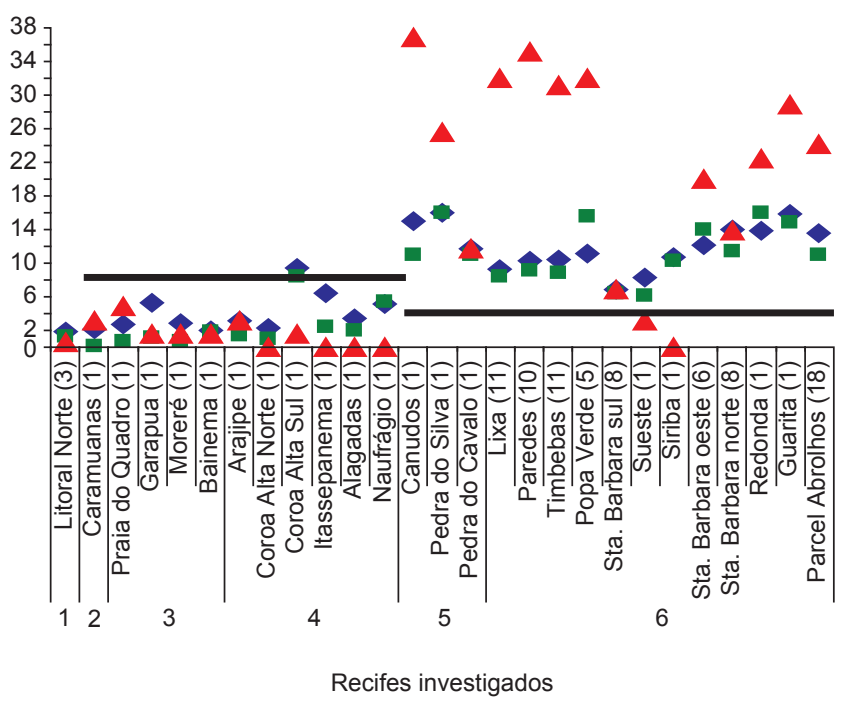

Figure 8. Quatro indicadores das condições vitais dos recifes da Bahia: \% da cobertura viva de coral (azul), densidade de colônias de corais com diâmetro maior que $20 \mathrm{~cm}$ (verde), densidade de recrutas de corais, colônias menores que $2 \mathrm{~cm}$ de diâmetro (vermelho), média do \% de mortalidade recente em corais (faixa em preto), evidenciando que os recifes costeiros ( 1 = Litoral Norte, 2 = Baía de Todos os Santos, 3 = Tinharé e Boipeba, 4 = Cabrália) localizados $<5 \mathrm{~km}$ da costa, apresentam condições vitais inferiores aos recifes localizados afastados da costa $>10 \mathrm{~km}$ (5 = Itacolomis, $6=$ Abrolhos $)$. (1) = número de estações. Fonte dos dados: Kikuchi et al. 2008.

Figure 8. Four coral indicators of the vitality of Bahian Reefs: \% live stone coral cover (blue), density of corals with diameter $>25 \mathrm{~cm}$ (green), density of coral recruits, colonies with diameter $<2 \mathrm{~cm}$ (red), mean $\%$ recent mortality (black line), showing that the nearshore reefs ( $1=$ North Coast, $2=$ Todos os Santos Bay, 3 = Tinharé and Boipeba Islands, $4=$ Cabrália), located $<5 \mathrm{~km}$ from the coastline are in poorer condition than the offshore reefs, which are located $>10 \mathrm{~km}$ from the coast $(5=$ Itacolomis, $6=$ Abrolhos $) .(1)=$ number of reef sites. Data from Kikuchi et al. 2008.

sido relativamente baixo, esta espécie de coral é um importante construtor dos recifes da região. Dados da literatura indicam que corais branqueados estão mais vulneráveis às infecções por patógenos causadores de diversos tipos de doenças e que estas doenças têm provocado a extinção de vastas áreas recifais (Bellwood et al. 2004, Kleypas \& Hoegh-Gulberg 2008).

Quais seriam, assim, as melhores alternativas para minimizar os efeitos sinérgicos de eventos sucessivos de branqueamento, e de impactos derivados de atividades antropogênicas? Segundo Wilkinson \& Souter (2008) - "Recifes com melhor manejo irão recuperar mais rapidamente que aqueles sob impacto humano". Isto significa que é preciso melhorar a proteção dos recifes, principalmente daqueles que são naturalmente mais resistentes ou tolerantes ao branqueamento, reduzindo as pressões locais nos próprios recifes e nos ecossistemas correlatos, para favorecer sua recuperação e/ou resiliência. Para isto é preciso evitar a destruição de manguezais, assim como controlar o desenvolvimento urbano das regiões costeiras. É necessário, também, que o branqueamento de coral esteja integrado nos esforços do manejo dos recifes e que os gestores conheçam como diferentes recifes irão responder ao aumento continuado da temperatura da água, nos próximos anos (MacField et al. 2008).

\section{Agradecimentos}

Os autores agradecem a todos aqueles que pelo menos uma vez fizeram parte do time AGRRA: Viviane Testa, Leo Dutra, Saulo 
Spanó, Cláudio Sampaio, Bertrand Feitosa, Marcelo Telles, Rafael Silva, Igor Cruz e Antonio Bonicci Neto, e aos membros da equipe de campo do programa MMAS (Marine Management Areas Sciences) Rodrigo Moura e Eric Joelico que participaram dos trabalhos de campo nos recifes dos Itacolomis no ano de 2005. Agradecimentos são extensivos aos dirigentes do Parque Nacional Marinho dos Abrolhos e da Conservação Internacional do Brasil, em Caravelas, pelo apoio logístico durante os trabalhos de campo, e a Igor Cruz pelo auxílio na aquisição dos dados das anomalias térmicas. Os trabalhos realizados durante estes anos foram financiados através projetos aprovados pelo Conselho Nacional do Desenvolvimento Científico e Tecnológico (CNPq, Proc. \#47218/03-1), pelo Ministério da Ciência e Tecnologia (MCT - SEPED - CGMGC, Proc. \#01200005221/2001-70), pela Fundação de Amparo a Pesquisa do Estado da Bahia (FAPESB, Proc. \# ET31/2004), pela National Oceanographic and Atmospheric Administration (NOAA) e pela Moore Foundation. Os dados dos recifes de Tinharé, Boipeba e Camamu foram obtidos através relatórios técnicos requisitados pela empresa El Paso e Gás Ltda, e da região de Cabrália pela Veracel Ltda. Z.M.A.N.L. e R.K.P.K. são bolsistas de produtividade em pesquisa do CNPq. Durante a realização das pesquisas M.D.M.O. recebeu bolsas da FAPESB (Mestrado) e do $\mathrm{CNPq}$ (Doutorado). Este artigo foi produzido sob os auspícios do Projeto Pró-Abrolhos, Instituto do Milênio 2006 - Convênio IOUSP/ $\mathrm{CNPq}$, que proporciona a continuidade desta pesquisa.

\section{Referências Bibliográficas}

ARONSON, R.B. \& SWANSON, D.W. 1997. Video surveys: Uni - and multivariate applications. Proc. 8th Int. Coral Reef Symp. Smithsonian Tropical Research Institute, Panamá City, 2:1441-1446.

BELLWOOD, D.R., HUGHES, T.P., FOLKE, C. \& NYSTROM, M. 2004. Confronting the coral reef crisis. Nature 429(6994):827-833.

BIRKELAND, C. 1997. Life and death of coral reefs. Chapman \& Hall, New York.

BROWN, B.E. 1997. Coral bleaching: causes and consequences. Coral Reefs 16(2):129-138

BOWN, B.E.. \& OGDEN, J.C. 1993. Coral bleaching - environmental stress can cause irreparable harm to coral reefs. Sci. Am. 268(1):64-70.

CARLETON, J.H. \& DONE, T.J. 1995. Quantitative video sampling of coral reef benthos: large-scale application. Coral Reefs 14(1):35-46.

CASTRO, C.B. \& PIRES, D.O. 1999. A bleaching event on a Brazilian coral reef. Rev. Bras. Oceanogr. 47(1):87-90.

CAUSEY, B. 2008. The history of massive coral bleaching and other perturbations in the Florida Keys. In Status of Caribbean coral reefs after bleaching and hurricanes in 2005 (C. Wilkinson \& D. Souter, eds.). Global Coral Reef Monitoring Network - GCRMN, Australian Institute of Marine Science, Townsville, p.61-67.

CONNELL, J.H. 1978. Diversity in tropical rain forest and coral reef. Science 199(4335):1302-1310.

COPPER, P. 1994. Ancient reef ecosystem expansion and collapse. Coral Reefs 13(1):3-11.

COSTA, C.F. \& AMARAL, F.M.D. 2002. Density and size differences in zooxanthellae from five reef-building coral species from Brazil. Proceed. $9^{\text {th }}$ Intern. Coral Reef Symp. Indonesian Institute of Sciences, Bali 1:159-162.

COSTA, C.F., AMARAL, F.M.D. \& SASSI, R. 2001. Branqueamento em Siderastrea stellata (Cnidaria, Scleractinia) da praia de Gaibu, Pernambuco, Brasil. Rev. Nordestina Biol. 15(1):15-22.

COSTA, C.F., COUTINHO, C.S., SASSI, R. \& BRITO, L.A.C. 2004 Microsymbionts of Siderastrea stellata (Cnidaria, Scleractinia) in coastal reefs of Cabo Branco, State of Paraíba, Northeastern Brazil. Trop. Oceanogr. 32(2):173-181.

DUTRA, L.X.C. 2000. O branqueamento de corais hermatípicos no Litoral Norte da Bahia associado ao evento El-Niño/98. Monografia de Bacharelado, Universidade Federal da Bahia, Instituto de Biologia, Salvador, Bahia.

DUTRA, L.X.C., KIKUCHI, R.K.P. \& LEÃO, Z.M.A.N. 2000. Thirteen months monitoring coral bleaching on Bahia's north coast, Brazil. Proceed. $9^{\text {th }}$ Int. Coral Reef Symp. Indonesian Institute of Sciences, Bali, p.373.

DUTRA, L.X.C., KIKUCHI, R.K.P. \& LEÃO, Z.M.A.N. 2006 . Todos os Santos Bay coral reefs, Eastern Brazil, revisited after 40 years. Proceed. $10^{\text {th }}$ Int. Coral Reef Symp. Japoneze Coral Reef society, Okinawa, p.1090-1095.

FAUTIN, D.G. \& BUDDEMEIER, R.W. 2004. Adaptive bleaching: a general phenomenon. Hydrobiologia 530/531(1-3):459-467.

FERREIRA, B.P. \& MAIDA, M. 2006. Monitoramento dos recifes de coral do Brasil - situação atual e perspectivas. Ministério do Meio Ambiente, Secretaria de Biodiversidade e Florestas, Brasília.

FITT, W.K., SPERO, H.J., HALAS, J., WHITE, M.W. \& PORTER, J.W. 1993. Recovery of the coral Montastrea annularis in the Florida Keys after the 1987 Caribbean "Bleaching event". Coral Reefs 12(2):57-64.

FRANCINI-FILHO, R.B., MOURA, R.L., THOMPSON, F., REIS, R.D., KAUFMAN, L., KIKUCHI, R.K.P. \& LEÃO, Z.M.A.N. 2008. Diseases leading to accelerated decline of reef corals in the largest South Atlantic reef complex (Abrolhos Bank, Eastern Brazil). Mar. Pol. Bul. doi:10.1016/j.marpolbul.2008.02.013.

GARDNER, T.A., COTE, I.M., GILL, F.A., GRANT, A. \& WATKINSON, A.R. 2003. Long-term region-wide declines in Caribbean corals. Science 301(5635):958-960.

GINSBURG, R.N., KRAMER, P., LANG, J.C., SALE, P. \& STENECK, R.S. 1998. AGRRA, Atlantic and Gulf Rapid Reef Assessment: http://agrra. org (último acesso em 01/2005).

GLYNN, P.W. 1990.Global Ecological Consequences of the 1982-1983 ElNiño Southern Oscillations. Elsevier Oceanography, Amsterdam.

GLYNN, P.W. 1993. Coral reef bleaching: ecological perspective. Coral Reefs 129(1):1-17.

GOLDBERG, J. \& WILKINSON, C. 2004. Status of coral reefs of the World 2004. GCRMN, Australian Institute of Marine Science, Townsville, p.67-92.

GOREAU, T.J. \& HAYES, R.L. 1994. Coral bleaching and ocean hotspots. Ambio 23(3):176-180.

GOREAU, T.J. \& MACFARLANE, A.H. 1990. Reduced growth rate of Montastrea annularis following the 1987-88 coral-bleaching event. Coral Reefs 8(4):211-215.

HUGHES, T.P., BAIRD, A.H., BELLWOOD, D.R., CARD, M., CONNOLLY, S.R., FOLKE, C., GROSBERG, R., HOEGH-GULDBERG, O., JACKSON, J.B.C., KLEYPAS, J., LOUGH, J.M., MARSHALL, P., NYSTRÖM, M., PALUMBI, S.R., PANDOLFI, J.M., ROSEN, B. \& ROUGHGARDEN, J. 2003. Climate change, human impacts and the resilience of coral reefs. Science 301(5635):929-933.

JACKSON, J.B.C., KIRBY, M.X., BERGER, W.H., BJORNDAL, K.A., BOTSFORD, L.W., BOURQUE, B.J., BRADBURY, R.H., COOKE, R., ERLANDSON, J., ESTES, J.A., HUGHES, T.P., STENECK, R.S., TEGNER, M.J. \& WARNER, R.R. 2001. Historical overfishing and the recent collapse of coastal ecosystems. Science 293(5530):629-636.

KIKUCHI, R.K.P., LEÃO, Z.M.A.N. \& OLIVEIRA, M.D.M. 2008. Diagnostic and monitoring program of coral reefs from Eastern Brazil. Rev. Biol. Trop. (in press).

KIKUCHI R, K.P., LEÃO, Z.M.A.N., TESTA, V., DUTRA, L.X.C. \& SPANÓ, S. 2003. Rapid assessment of Abrolhos reefs, eastern Brazil (Part 1: stony corals and algae) Atoll Res. Bull. 496:172-188.

KLEYPAS, J. \& HOEGH-GULDBERG, O. 2008. Coral reefs and climate change: susceptibility and consequences. In Status of Caribbean coral reefs after bleaching and hurricanes in 2005 (C. Wilkinson \& D. Souter, eds.). Global Coral Reef Monitoring Network - GCRMN, Australian Institute of Marine Science, Townsville, p.19-29.

KNOWLTON, N. \& JACKSON, J.B. 2008. Shifting baselines, local impacts and global change on coral reefs. PloS Biol. 6(2):0215-0220. 
KÜHLMANN, D.H.H. 1988. The sensitivity of coral reefs to environmental pollution. Ambio 17(1):13-21.

LEÃO, Z.M.A.N., KIKUCHI, R.K.P. \& TESTA, V. 2003. Corals and Coral Reefs of Brazil. In Latin America Coral Reefs (J. Cortês ed.). Elsevier Publisher, Amsterdam, p.9-52.

LEÃO, Z.M.A.N., KIKUCHI, R.K.P., TESTA, V., TELLES, M.D., PEREIRA, J.L.J., DUTRA, L.X.C. \& SAMPAIO, C.L.S. 1999. First coral reef assessment in the southern hemisphere applying the AGRRA rapid protocol (Caramuanas Reef, Bahia, Brazil). International Conference on Scientific Aspects of Coral Reef Assessement, Monitoring, Restoration, Fort Lauderdale, p.422-423.

MACFIELD, M., BOOD, N., ARRIVILLAGA, A., RINOS, A.F. \& VIRUEL, R.M. 2008. Status of the Mesoamerican reefs after the 2005 coral bleaching event. In Status of Caribbean coral reefs after bleaching and hurricanes in 2005 (C. Wilkinson \& D. Souter, eds.). Global Coral Reef Monitoring Network - GCRMN. Australian Institute of Marine Science, Australian, p.45-60.

MARGALEF, R. 1989. Ecologia. Ediciones Omega, Barcelona.

McCLANAHAM, T.R. 2004. The relationtship between bleaching and mortality of common corals. Mar. Biol. 144(6):1239-1245.

McCLANAHAM, T.R., ATEWEBERHAM, M., GRAHAM, N.A.J., WILSON, S.K., RUIZ-SEBASTIAN, C., GUILLAUME, M.M.M. \& BRUGGEMANN, J.H. 2007. Western Indian Ocean coral communities: bleaching responses and susceptibility to extinction. Mar. Ecol. Prog. Ser. 337:1-13.

MICHALEK-WAGNER, K. \& WILLIS, B. 2001. Impacts of bleaching on the soft coral Lobophyton compactum, 1. Fecundity, fertilization and offspring viability. Coral Reefs 19(3):231-239.

MIGOTTO, A.E. 1997. Anthozoan bleaching on the southeastern coast of Brazil in the summer of 1994. In Proc. Intern. Conference on Coelenterate Biology, 6, 1995. ICCB, Leeuwenhorst, p.329-335.

MOBERG, F. \& FOLKE, C. 1999. Ecological goods and services of coral reef ecosystems. Ecol. Econ. 29(2):215-233.

MULLER-PARKER, G. \& D'ELIA, S.F. 1997. Interactions between corals and their symbiotic algae. In Life and depth of coral reefs (C. Bikerland, ed.). Chapman and Hall, New York., p.96-112.

MUSCATINE, L. 1990. The role of symbiotic algae in carbon and energy flux in reef corals. In Ecosystems of the world 25: Coral Reefs (Z. Dubinsky, ed.). Elsevier, New York, p.75-84.

OLIVEIRA, M.D.M., KIKUCHI, R.K.P., LEÃO, Z.M.AN. \& DUTRA, L.X.C. 2004. Coral bleaching in Brazil, Western South Atlantic. In Abstract $10^{\text {th }}$ Intern. Coral Reef Symp. Japoneze Coral Reef Society, Okinawa, p.406.
PAGE, C., COLEMAN, G., NINIO, R. \& OSBORNE, K. 2001. Surveys of benthic reef communities using underwater video. Long-term Monitoring of the Great Barrier Reef Standard Operational Procedure Number 2. Australian Institute of Marine Science, Townsvile, 45p.

PANDOLFI, J.M., BRADBURY, R.H., SALA, E., HUGHES, T.P., BJORNDAL, K.A., COOKE, R.G., McARDLE, D., McCLENACHAN, L., NEWMAN, M.J., PAREDES, G., WARNER, R.R. \& JACKSON, J.B.C. 2003. Global trajectories of the long-term decline of coral reef ecosystems. Science 301(5635):955-958.

RODRIGUEZ-RAMIREZ, A., BASTIDAS, C., RODRIGUEZ, S., LEÃO, Z., KIKUCHI, R., OLIVEIRA, M., GIL, D., GARZON-FERREIRA, J., REYES-NIVIA, M.C., NAVAS-CAMACHO, R., SANTODOMINGO, N., DIAZ-POLIDO, G., VENERA-PONTON, D., FLOREZ-LEIVA, L., RANGEL-CAMPO, A., OROZCO, C., MARQUEZ, J.C., ZEA, S., LOPEZ-VICTORIA, M., SANCHEZ, J.A. \& HURTADO, M.C. 2008. The effects of coral bleaching in Southern Tropical America: Brazil, Colombia and Venezuela. In Status of Caribbean coral reefs after bleaching and hurricanes in 2005. (C. Wilkinson \& D. Souter, eds.). Global Coral Reef Monitoring Network - GCRMN. Australian Institute of Marine Science, Townsville, p.105-114.

STANLEY JR., G.D. 2006. Photosymbiosis and the evolution of modern coral reefs. Science 312(5775):857-858.

SZMANT, A.M. \& GASSMAN, N.J. 1990. The effects of prolonged bleaching on the tissue biomass and reproduction of the reef coral Montastrea annularis. Coral Reefs 8(4):217-224.

WALTHER, G.R., POST, E., CONVEY, P., MENZEL, A., PARMESAN, C., BEEBEE, T.J.C., FROMENTIN, J.M., HOEGH-GULDBERG, O. \& BAIRLEIN, F. 2002. Ecological responses to recent climate change. Nature 416(6879):389-395

WILKINSON, C. 2002. Status of coral reefs of the world 2002. GCRMN. Australian Institute of Marine Science, Townsville, Australia, p.7-44.

WILKINSON, C. \& SOUTER, D. 2008. Status of Caribbean coral reefs after bleaching and hurricanes in 2005. Global Coral Reef Monitoring Network - GCRMN. Australian Institute of Marine Science, Townsville, p.3-13.

WILKINSON, C., LAUDEN, O., CESAR, H., HODGSON, G., RUBENS, J. \& STRONG, A. 1999. Ecological and socioeconomic impacts of 1998 coral mortality in the Indian Ocean. An ENSO impact and a warning of future change? Ambio 28(4):188-196.

Recebido: 09/11/07 Versão revisada recebida em:27/03/08 Publicado em 25/07/08 